\title{
Design of International Transfer Market for Iranian footballer
}

Mousavi, S, E. (Ph.D. Candidate). University of Tehran, Tehran, Iran

Goodarzi, M. (Ph.D). University of Tehran, Tehran, Iran

Khabiri, M. (Ph.D). University of Tehran, Tehran, Iran

Alidoost Ghahfarrokhi, E. (Ph.D). University of Tehran, Tehran, Iran

Received: 2017 - 6 - 25

Accept: $2018-7-23$

\section{Abstract}

The soccer players transfer market is a global market and there is a huge turnover in this market. The aim of this study is to Design of International Transfer Market for Iranian footballer. The current stude methodology was Exploratory mixed method. A questionnaire and interview was used to collect data. The results showed that six factors of players technical performance, non-technical factors players, government, the Football Association, the club and the player's agent was effective on Iranian international footballer transfers that presented by modeling. In the end, it can be said for active in International Transfer Market for soccer players, all of the stakeholders must fulfill of their role by do best of their duties that was in the form of statements extracted.

Keywords: Transfer Market, Soccer Players, Sport Industry, Human Resources, Footballer Export. 


\section{طراحى الكوى بازار نقل و انتقالات بينالمللى فوتباليستهاى ايرانى}

$$
\begin{aligned}
& \text { سيد اسفنديار موسوى *، محمود گودرزى***، محمد خبيرى***، ابراهيم عليدوست قهفرخى **** }
\end{aligned}
$$

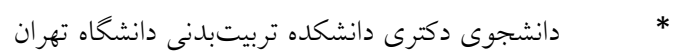

$$
\begin{aligned}
& \text { ～～** }
\end{aligned}
$$

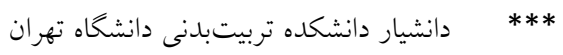

$$
\begin{aligned}
& \text { **** }
\end{aligned}
$$

در فوتبال بازيكن مستعد، در بازارى كه مختص ورزش است و بازار نقل و انتقالات ناميده مى شود تجارت مى شود. اين

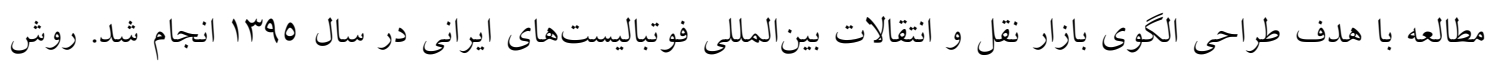

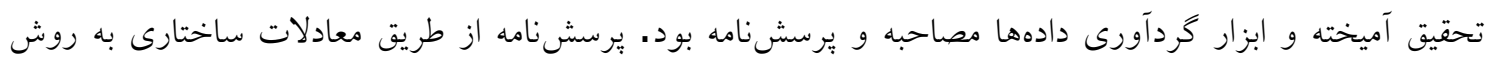

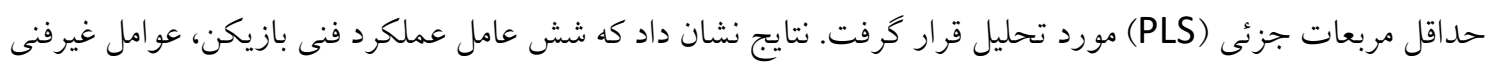

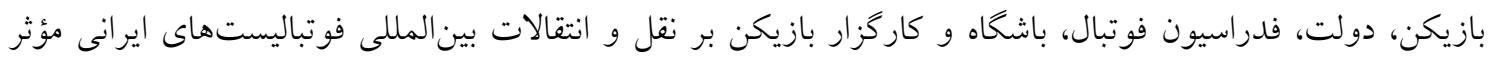

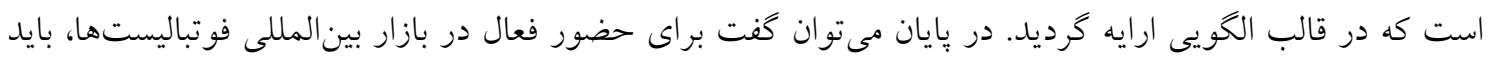

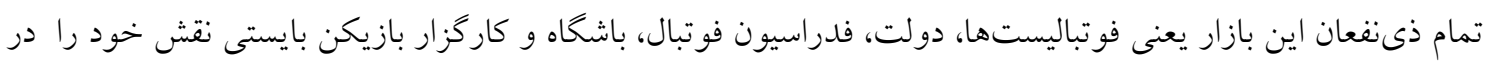
قالب كويههاى استخراج شده به درستى ايفا نمايند.

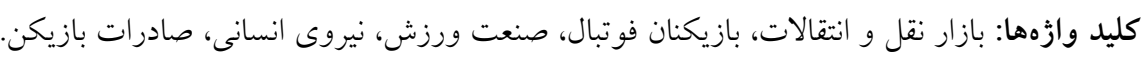


باشكاه، واحد بنيادين ورزش مدرن است (1). مهمترين جزء براى يك باشكاه ورزشى خصوصاً باشكاه فوتبال، بازيكنان آن است.

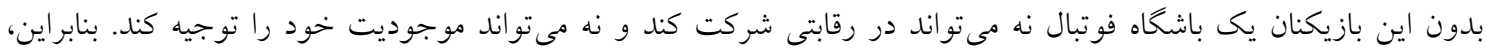

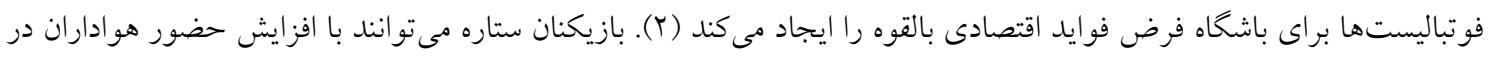

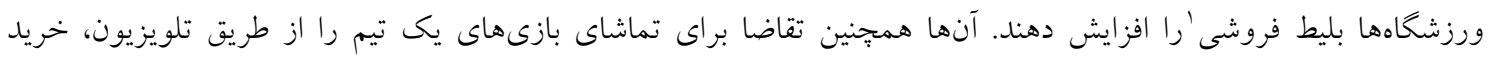

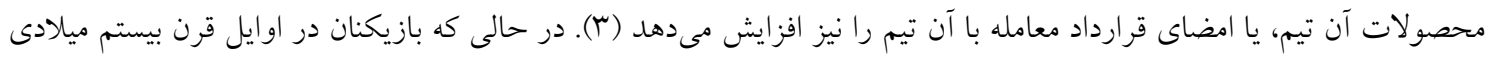

به سختى مقدار يول زيادى دريافت مىكردند، فضاى جديد رقابت را براى امضاء قرارداد با بازيكنان افزايش داده است (rاس).

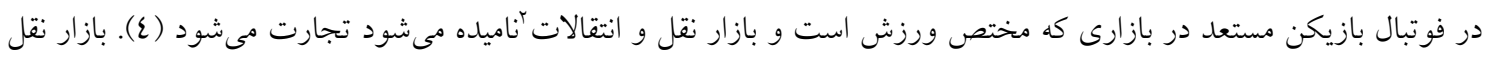

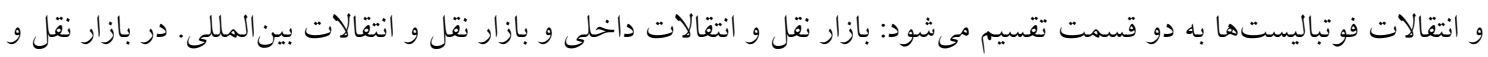

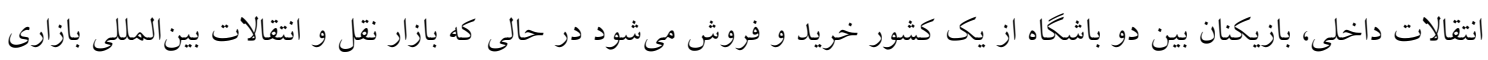

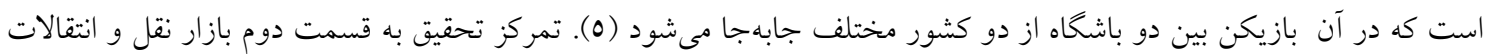

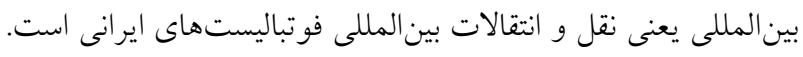

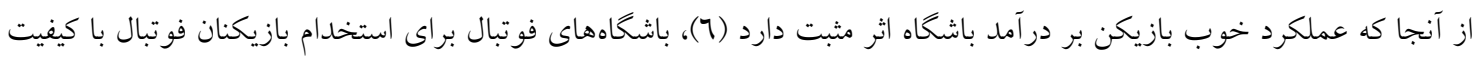

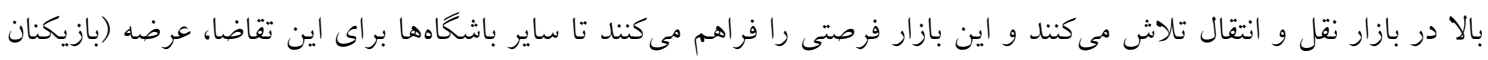

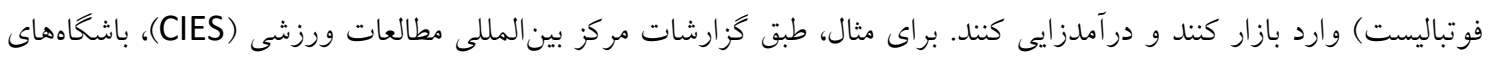

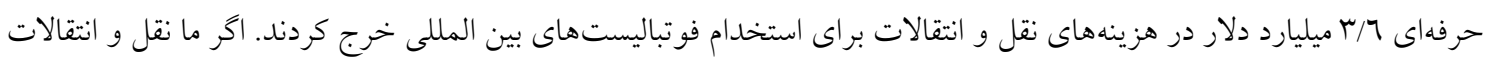

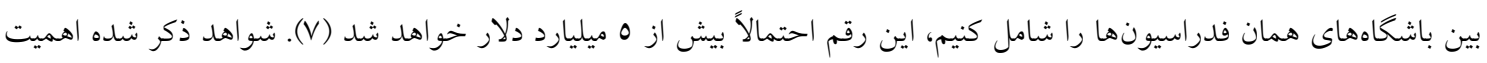

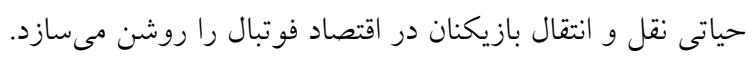

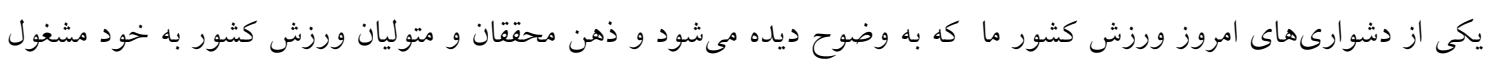

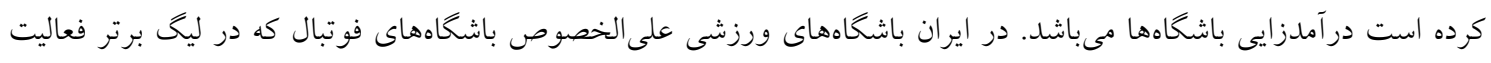

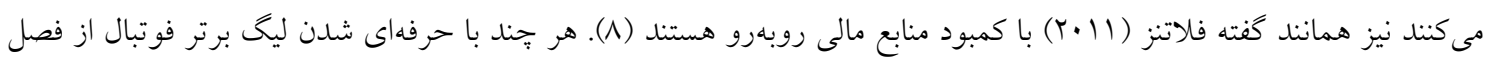

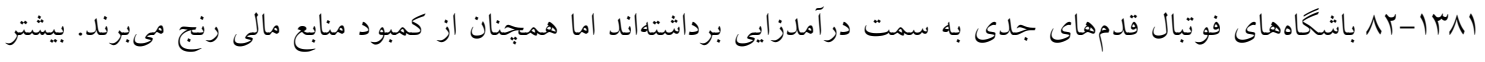

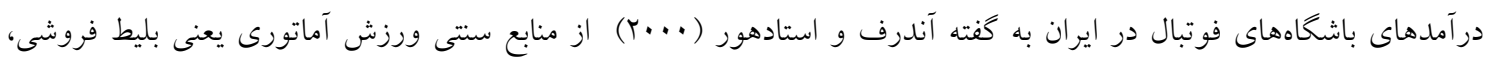

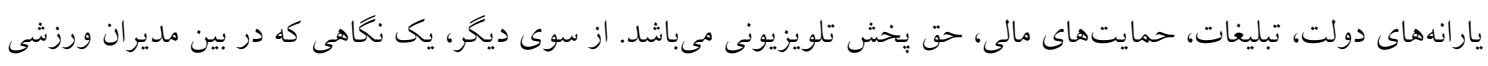

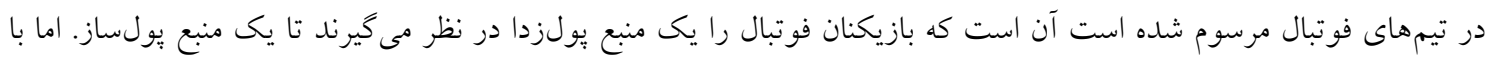

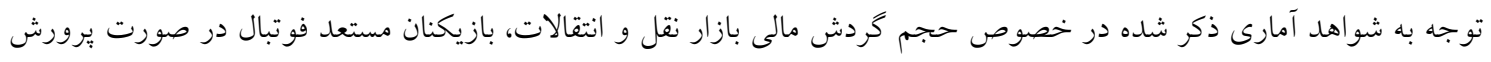

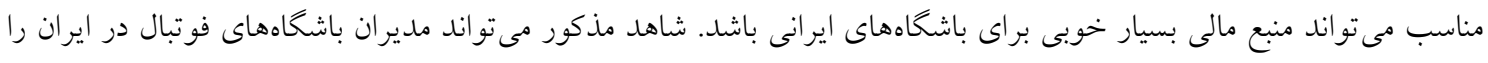

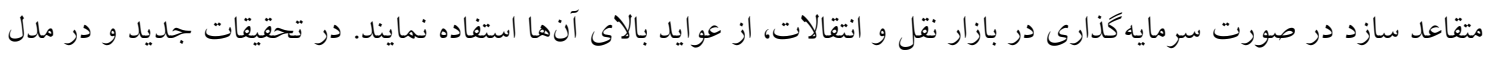

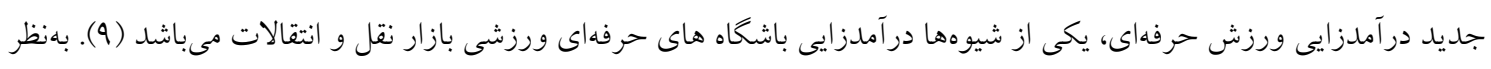

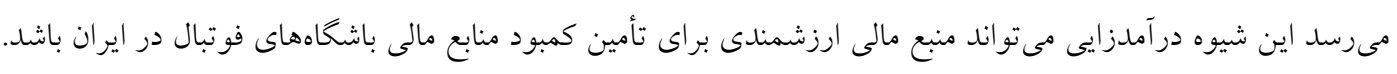

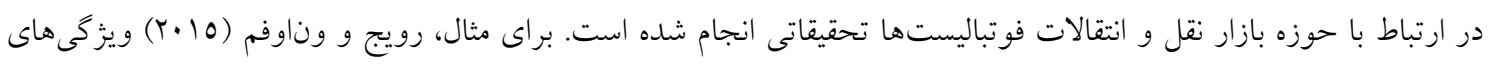

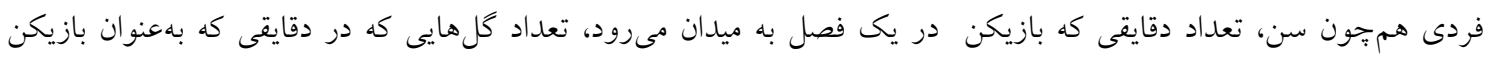

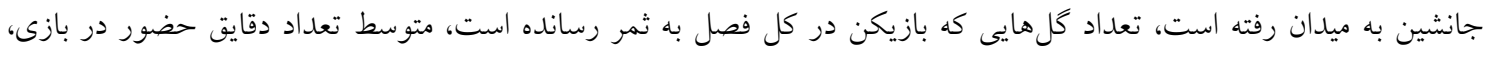

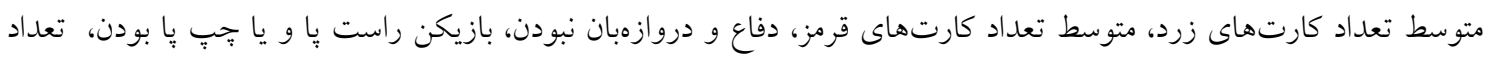

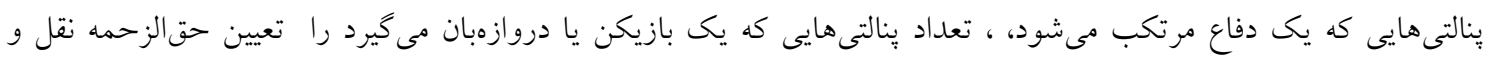

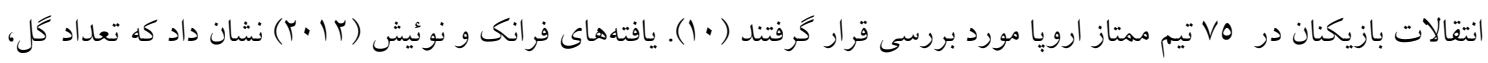




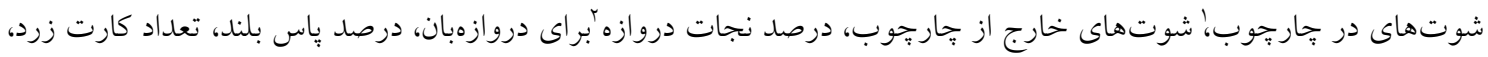
تعداد كارت قرمز، تعداد كل زده از روى ضربان بنالتى در محبوب شدن و فوق ستاره شدن فوتباليستها مؤثر است (11). يافتههاى

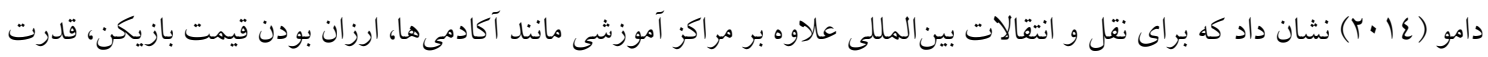
جانهزنى كارگزارها در خريد و فروش بازيكنان، قوانين حقوقى بر بازار نقل و انتقالات بين المللى بازيكنان برزيلى نقش دارند.

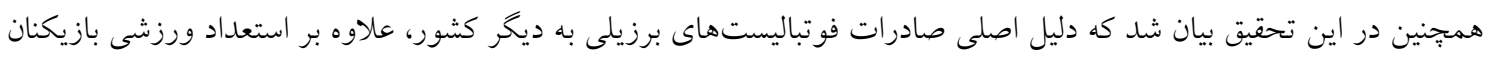

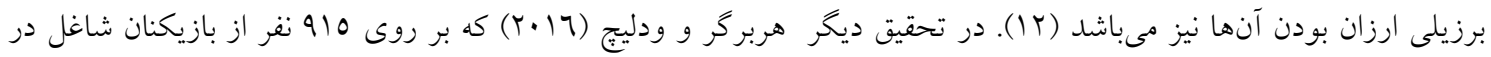

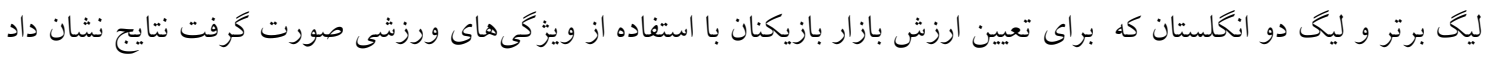

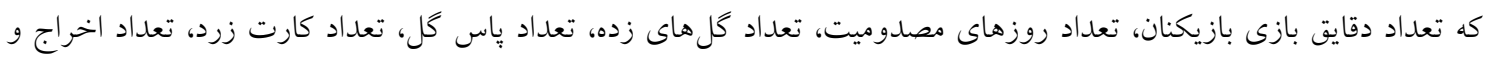

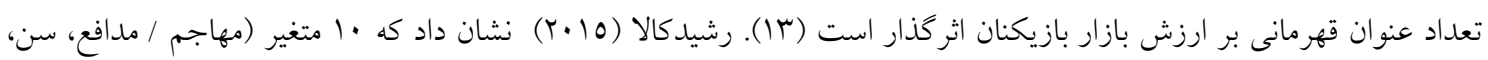

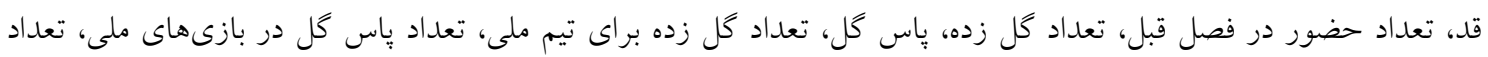
حضور در تيم ملى، موقعيت باشگاه خريدار و فروشنده)، 70 \% حقالزحمه ارزش بازار بازيكنان ليگ برتر فوتبال انخلستان را

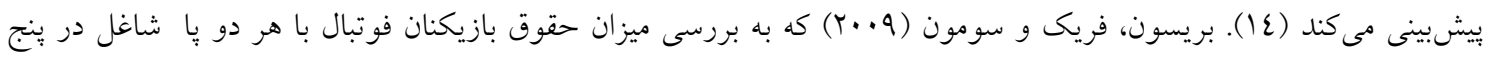

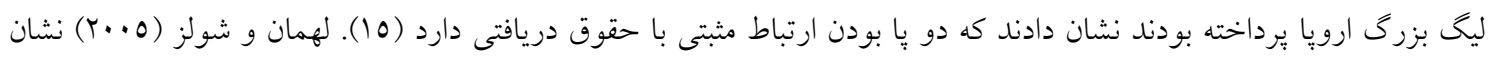

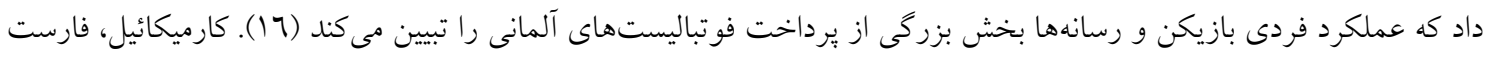

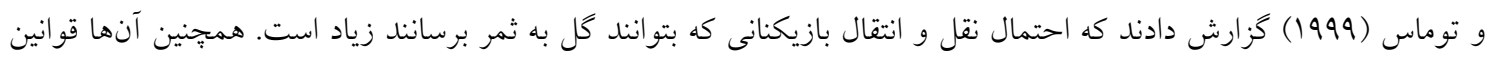

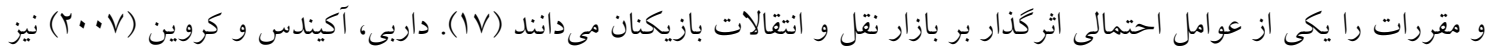

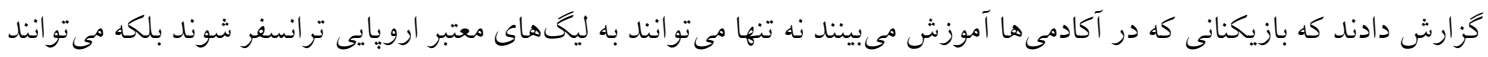

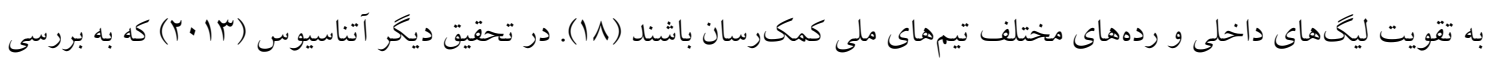
واكنش بازار به نقل و انتقالات فوباليستها در ارويا برداخته بود دريافت كه فروش بازيكنان منجر به بازده غيرطبيعى مثبت سهام

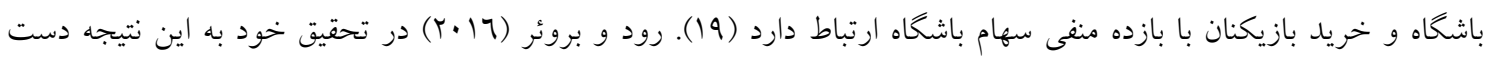

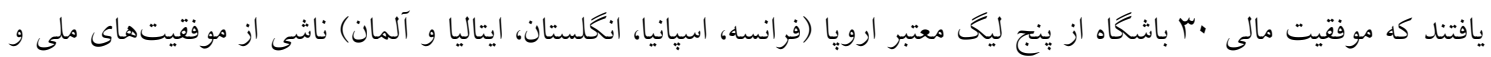

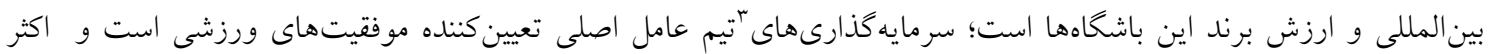

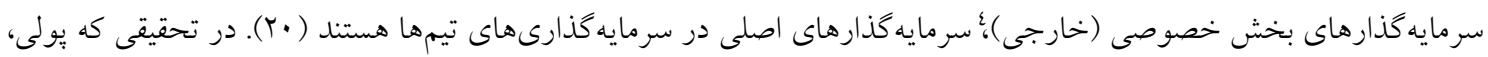

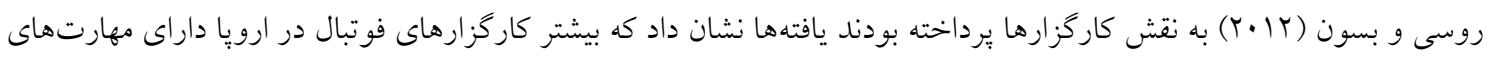

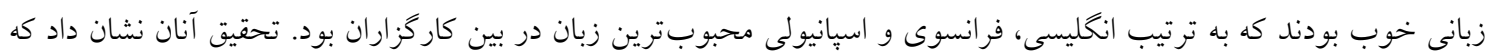
دو سوم ياسخ گويان به موكلان خود (بازيكنان) در بازاريابى و قراردادهاى صحهذذارى كمك مى كردند. به طور شخفت آور، تنها

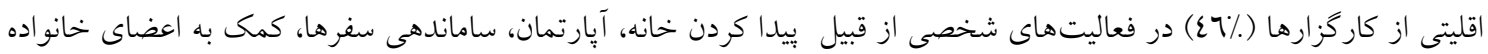

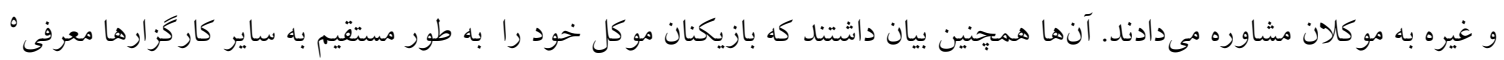

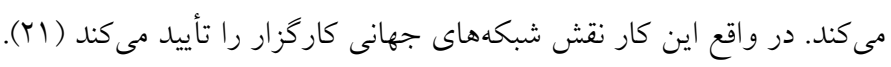

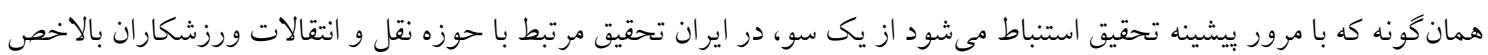
نقل و انتقالات فوتباليستها يافت نشد. از سوى ديخر، عمده تحقيقات در حوزه نقل و انتقالات فوتباليستها به ينج ليخ بزرى ارويا و ليخ بزرگ فوتبال (موسوم به MLS) انجام شده است كه شايد دليل عمده آن بنا به كفته شفافيت مالى در اين ليخها باشد.

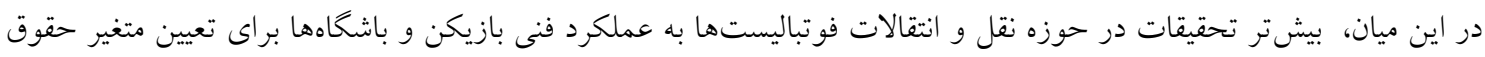

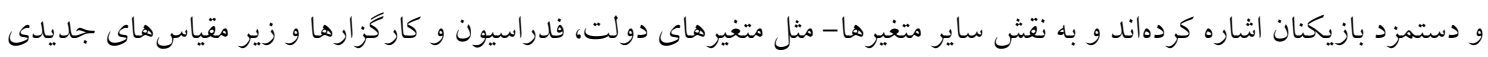

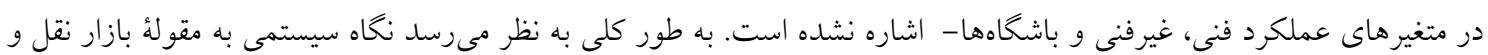

I Shots on Sarget r. Saves

rInvestments
؟Private majority investors - Represent 


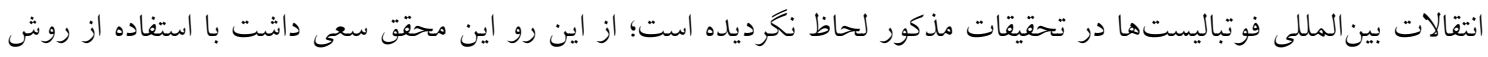

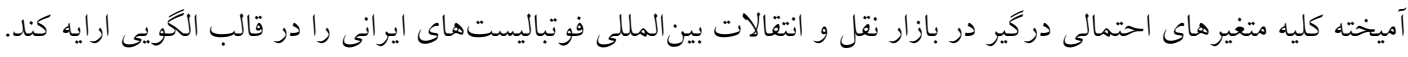

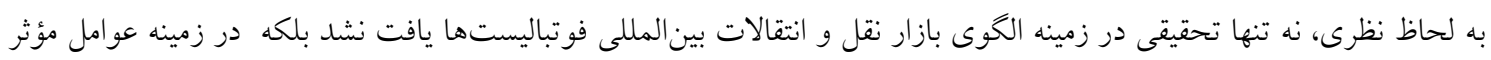

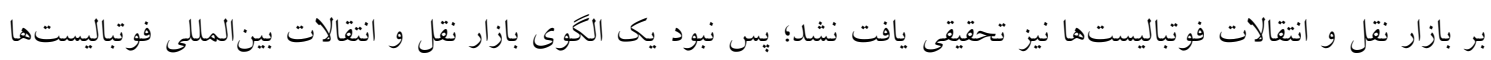

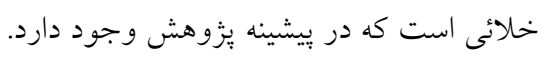
با انجام تحقيق حاضر ضمن بـى بردن به اهميت نقل و انتقلات فوتباليستها در درآمدزايى باشخاههاى فوتبال، انتظار مىرود با باليا

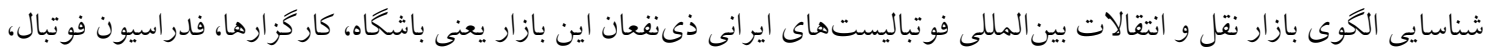

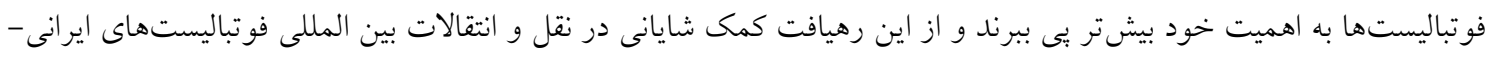

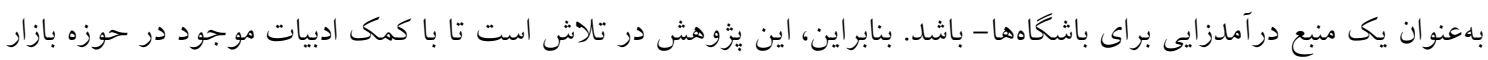

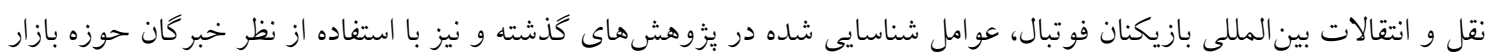

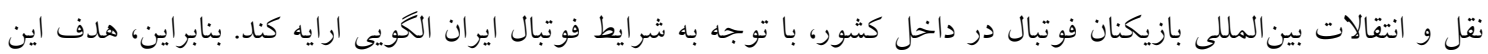
يُزوهش طراحى الكوى بازار نقل و انتقالات بين المللى فوتباليستهاى ايرانى مىباشد.

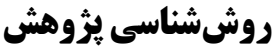

روش تحقيق حاضر از نظر نتيجه توسعهاى، از نظر هدف اكتشافى و به لحاظ نوع دادهها از نوع آميخته است. اين طرح با جمع آورى

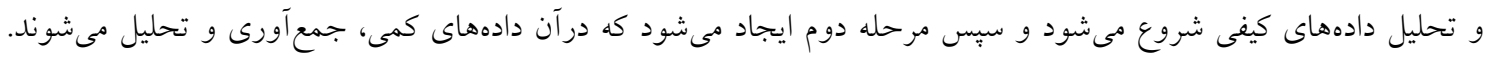

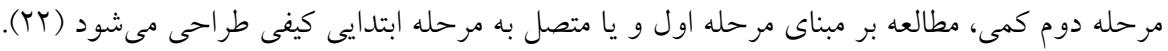

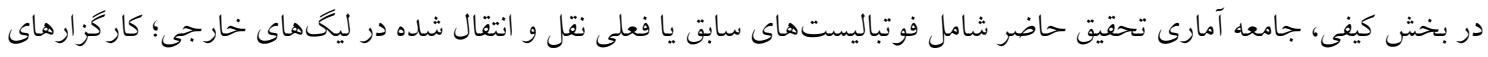

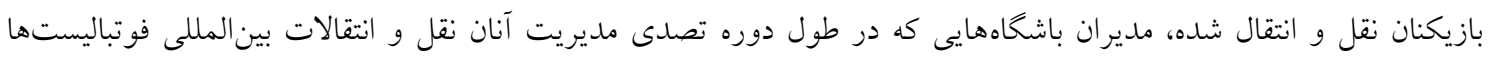

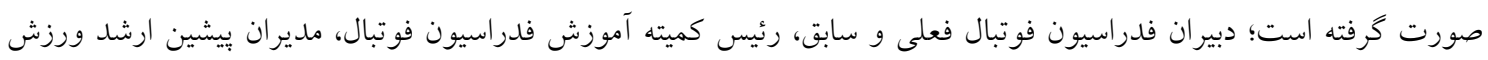

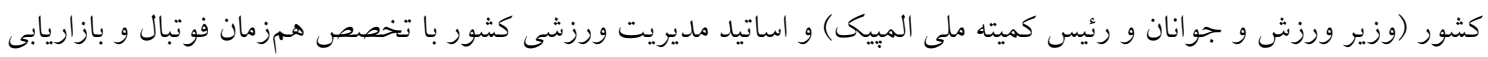
بود. نمونه كيرى در مرحله مصاحبه با استفاده از روش دلفى به دو صورت هدفمند و طبقهاى بود. در مجموع با •r نفر مصاحبه انجام كرفت. در بخش كمى، جامعه آمارى شامل مدير عامل هاى ليخ برتر و ليخ يك فوتبال كشور در فصل

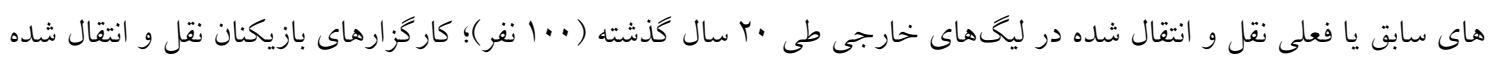

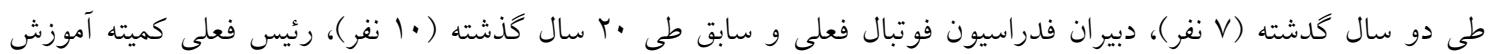

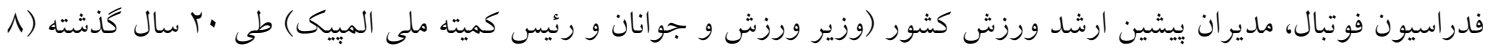

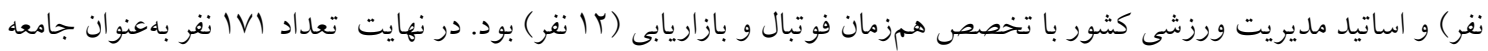

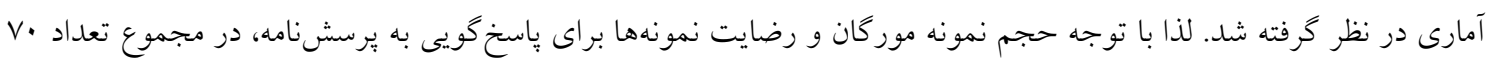

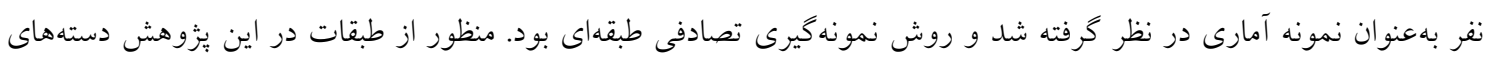

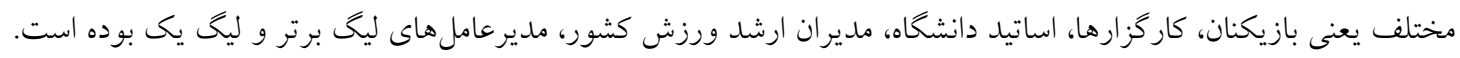
ابزار جمع آورى اطلاعات در اين تحقيق در مرحله كيفى مصاحبه عميق و روش دلفى بود. ابتدا در حوزه نقل و انتقالات بازيكنان

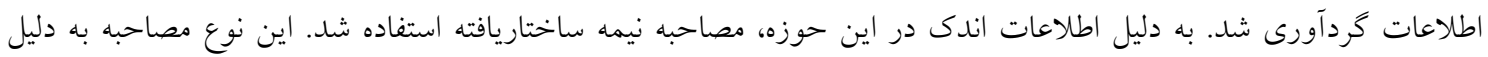

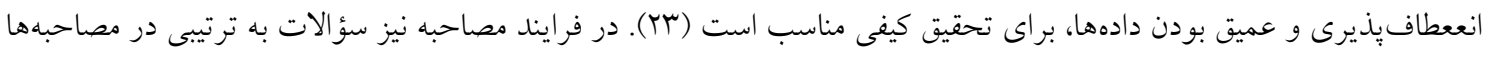

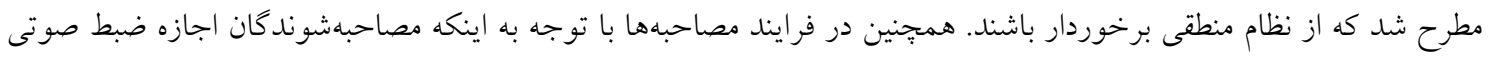

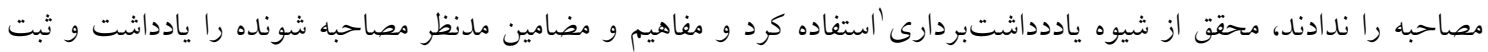

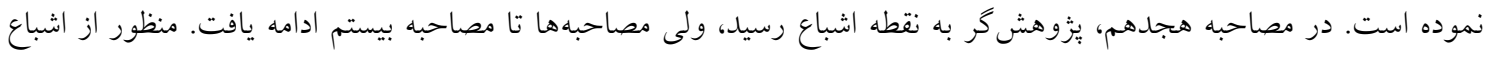


نظرى، قضاوتى است كه يُوهش گر بر اساس آن تصميم مى گيرد كه نياز به جمع آورى اطلاعات بيشتر وجود ند ندارد و و اطلاعات

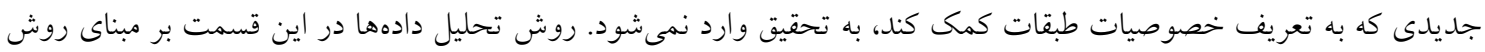

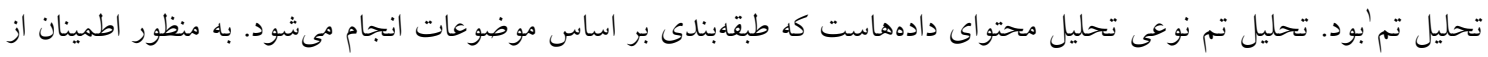

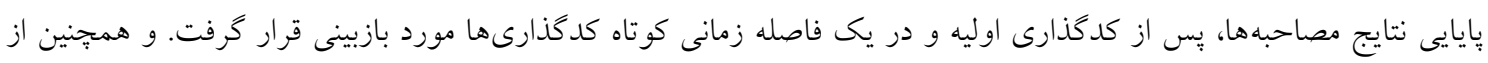

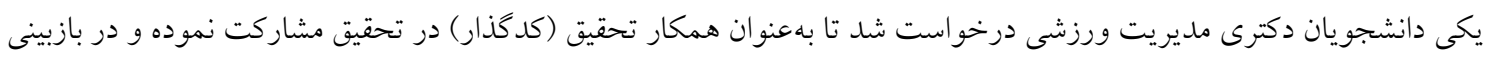

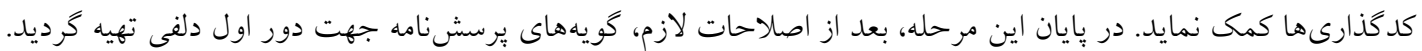

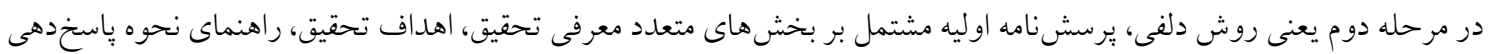

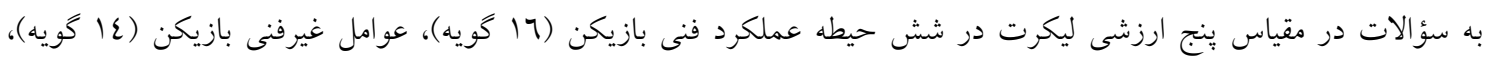

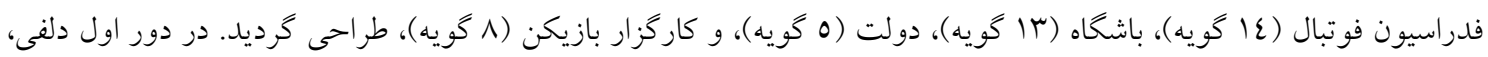

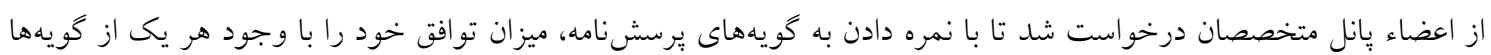

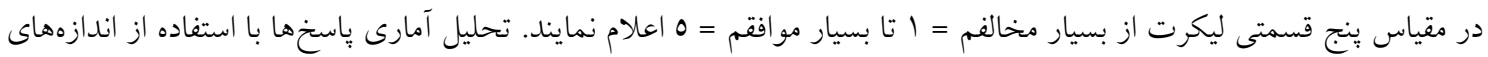
مركزى و شاخص بر اكندگى در نرم|فزار SPSS انجام و محدوده ميان خاركى، ميانكين و انحر اف معيار امتياز گويهها تعيين گرديد

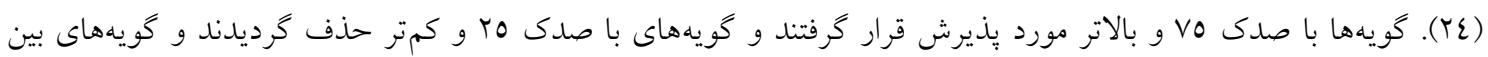

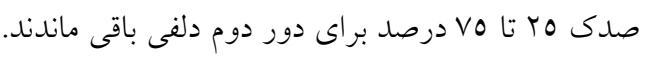

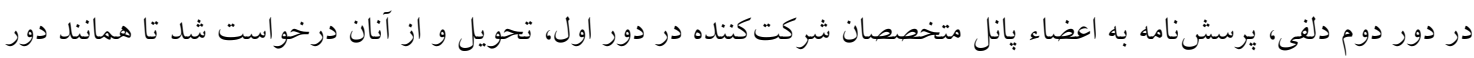

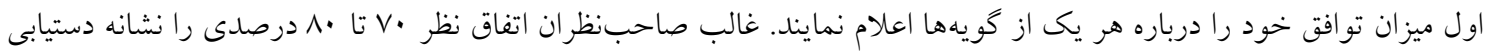

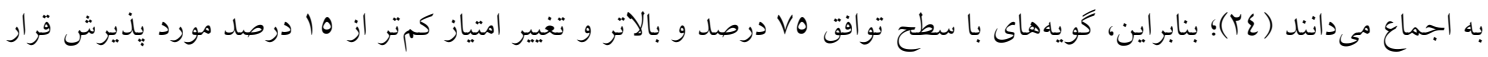

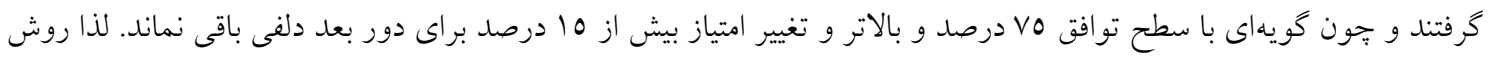

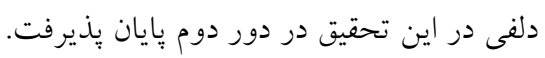

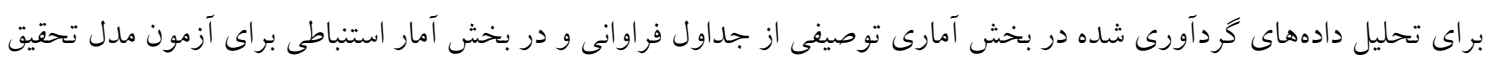

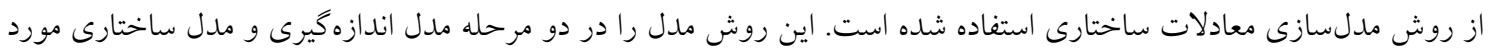

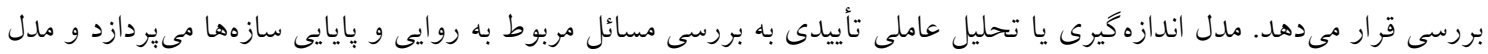

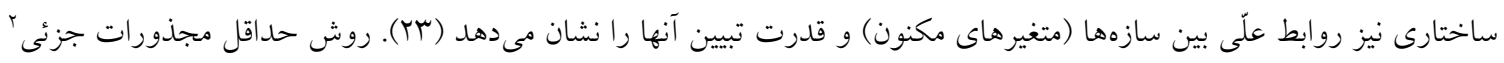

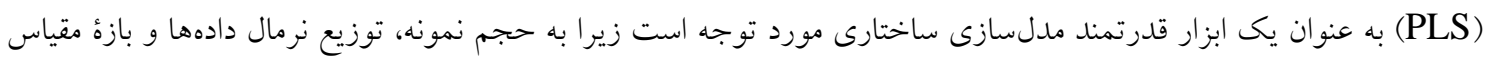

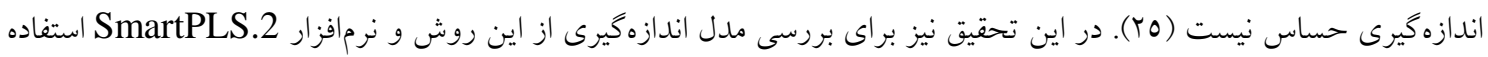

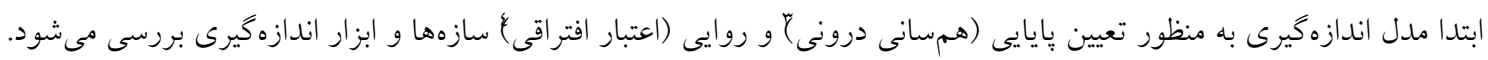

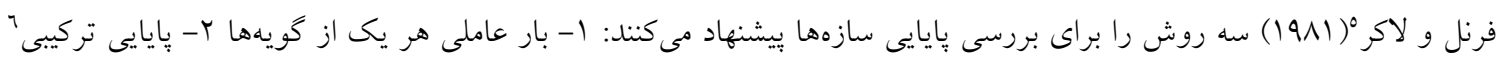

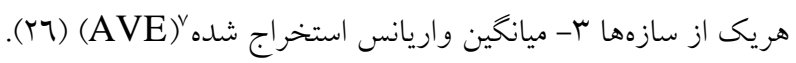

توزيع فراوانى افراد مصاحبهشونده در شش كروه بافئ بازيكنان نقل و انتقال شده، رئيس و دبير فدراسيون فوتبال، كاركزار بازيكنان نقل

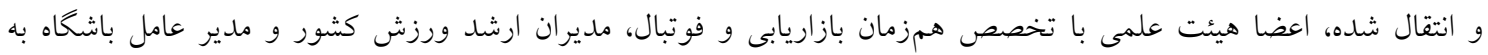

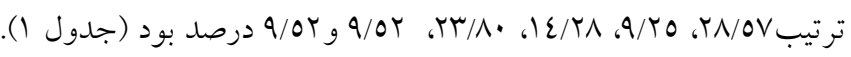


جدول ا. توزيع فراوانى افراد مصاحبه شونده

\begin{tabular}{|c|c|c|}
\hline درصد & تعداد & افراد مصاحبهشونده \\
\hline YN/OV & 7 & بازيكن نقل و انتقال شده (به ليخهاى ايتاليا، بلثيك، مجارستان، امارات، قطر، كويت) \\
\hline $9 / 0 Y$ & r & رئيس و دبير فدراسيون فوتبال \\
\hline $\mid \varepsilon / Y \wedge$ & r & كارگزار بازيكنان نقل وانتقال شده \\
\hline$r \mathrm{r} / \mathrm{M} \cdot$ & 0 & اعضاء هيئت علمى با تخصص همزمان بازاريابى و فوتبال \\
\hline $9 / 0 \mathrm{r}$ & r & مديران ارشد ورزش كشور (وزير ورزش فعلى و رئيس اسبق كميته ملى المييك) \\
\hline $9 / 0 \mathrm{r}$ & r & مدير عامل باشخاه \\
\hline $1 \cdots$ & $r$. & \\
\hline
\end{tabular}

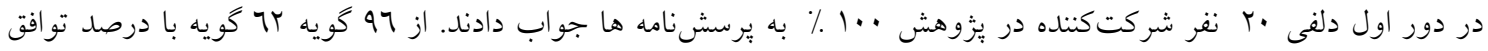

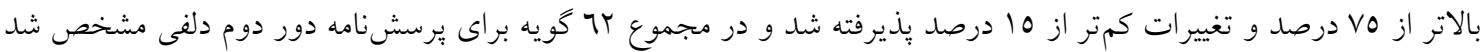

جدول r. تعداد گويههاى بذ ير فته شده، حذف شده در هر بعد در دور اول دلفى

\begin{tabular}{|c|c|c|c|c|}
\hline تعداد كويههاى ورود به دور دوم & كويههاى حذف شده & كويه هاى بذيرفته شده & تعداد كويه & ابعاد \\
\hline 10 & v & 10 & rr & عملكرد فنى بازيكن \\
\hline ir & 9 & ir & r & عوامل غيرفنى بازيكن \\
\hline $1 \varepsilon$ & $r$ & $1 \varepsilon$ & IV & قش فدراسيون فوتبال \\
\hline 11 & 0 & 11 & 17 & نقش باشگاه \\
\hline 0 & $\varepsilon$ & ० & 9 & نقش دولت \\
\hline 0 & $\varepsilon$ & 0 & 9 & نقش كار گزار بازيكن \\
\hline$T Y$ & $T \varepsilon$ & $T Y$ & $9 \varepsilon$ & مجموع \\
\hline
\end{tabular}

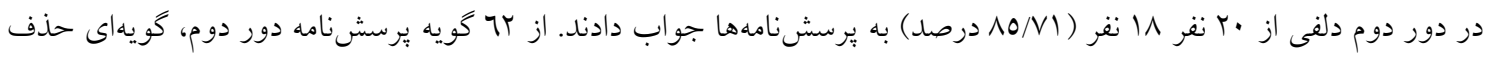

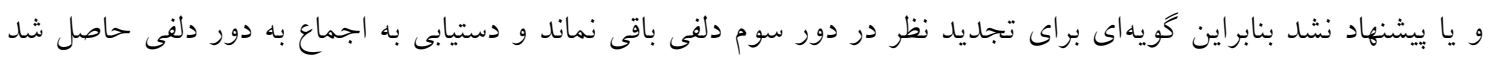

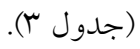

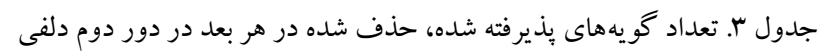

\begin{tabular}{|c|c|c|c|}
\hline كويههاى حذف شده & كويههاى بذير فته شده & تعداد كويه & ابعاد \\
\hline- & 10 & 10 & عملكرد فنى بازيكن \\
\hline- & Ir & Ir & عوامل غيرفنى بازيكن \\
\hline- & $1 \varepsilon$ & $1 \varepsilon$ & نقش فدراسيون فوتبال \\
\hline- & 11 & 11 & نتش باشكاه \\
\hline- & 0 & 0 & نقش دولت \\
\hline- & 0 & 0 & نقش كار كزار بازيكن \\
\hline- & $\pi$ & $\pi$ & مجموع \\
\hline
\end{tabular}

تصويب يرسشنامه نهايى: در اين مرحله يس از دستيابى به اجماع، ميزان امتياز كويههاى يذيرفته شده دور اول و دوم دلفى در

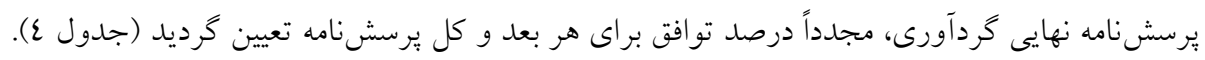


جدول F. تعداد گو يهها، ابعاد و درصد توافق اعضاء يانل تخصصان با برسشنامه نهايى حاصل از روش دلفى

\begin{tabular}{|c|c|c|}
\hline درصد توافق & 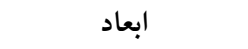 & تعداد گويهها \\
\hline$V \wedge / 91$ & عملكرد فنى بازيكن & 10 \\
\hline$V T / 1 \varepsilon$ & عوامل غيرفنى بازيكن & IT \\
\hline$\Lambda 0 / M_{1}$ & نقش فدراسيون فوتبال & $1 \varepsilon$ \\
\hline$\Lambda N / T r$ & نقش باشخاه & 11 \\
\hline$\wedge 7 / 9 \mu$ & نقش دولت & 0 \\
\hline $19 / T_{0}$ & نقش كارگزار بازيكن & 0 \\
\hline$\wedge \varepsilon / 19$ & مجموع & $7 r$ \\
\hline
\end{tabular}

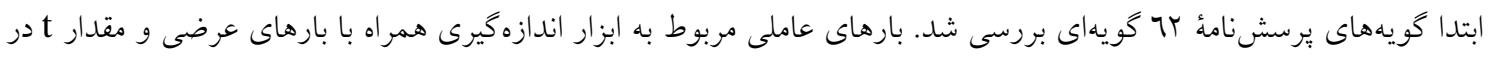

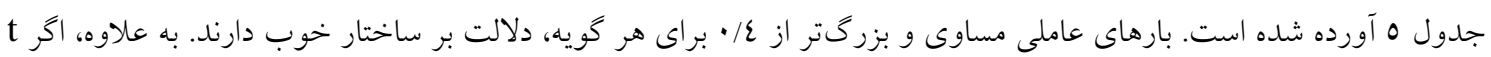

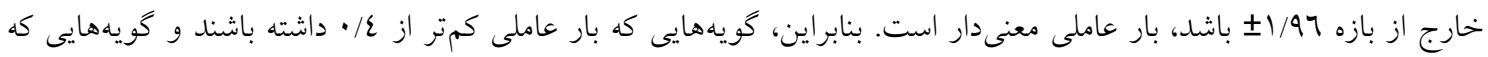

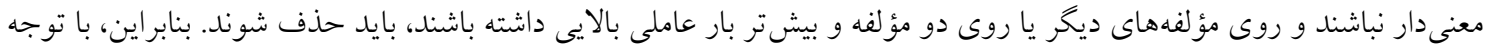

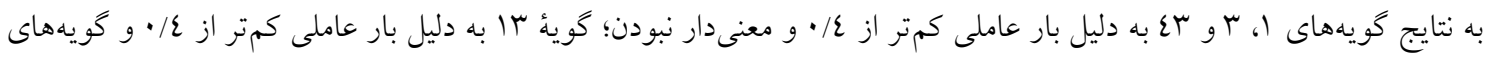

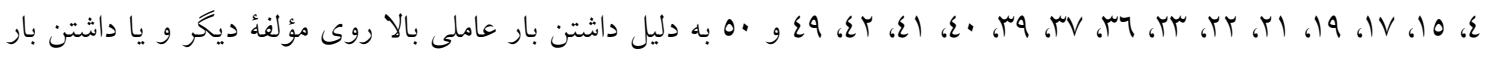

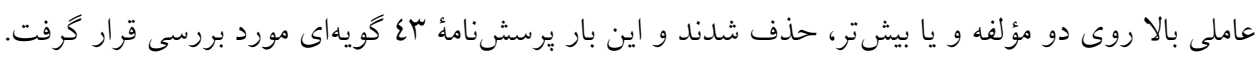

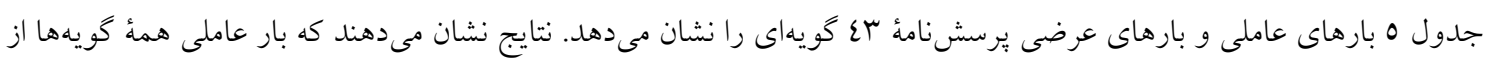

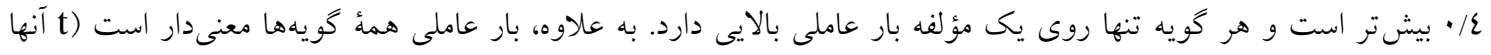

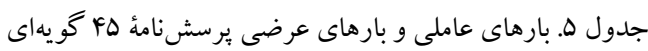

\begin{tabular}{|c|c|c|c|c|c|c|c|}
\hline t مقدار & عملكرد فنى & عوامل غيرفنى & دولت & فدراسيون & باشكاه & كاركزار & \\
\hline$r / r \cdot 90 V 7$ & $\cdot / \varepsilon \varepsilon \wedge \Lambda \varepsilon \wedge$ & ./1797rE & $\cdot / 109 \wedge \varepsilon V$ & . r. roz. & • rqrqVr & ./lErovা & r \\
\hline$\varepsilon / A \cdot 1 \cdot \varepsilon \tau$ & . &.$/ 117010$ & ./IrrqIA & $\cdot / \varepsilon \mid \varepsilon 77 V$ & $\cdot / \varepsilon \mid r \cdot V 0$ & $\cdot /|7 V| \cdot \wedge$ & 0 \\
\hline$V / T \backslash \varepsilon \mid \cdot l$ & $\cdot / \wedge \varepsilon \| \Lambda$ & $\cdot / T \cdot 0 \Sigma 1 \wedge$ & . / orv7o & $\cdot / r I \cdot \varepsilon r V$ & $\cdot / r q \cdot \wedge 0$ & $\cdot / \| \wedge r \wedge \mid$ & 7 \\
\hline$T / V_{0} \cdot r_{0}$ & $\cdot / 7 r \varepsilon 7 \cdot \varepsilon$ & . / & $\cdot / \varepsilon 01 \cdot r \mu$ & ./TKMrq & $\cdot / 1 \vee q \cdot v q$ & - /lOr. rA & v \\
\hline $7 / 0109 \cdot 1$ & 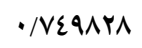 & • & . $/$ ¿qVOr & - ro\& & $\cdot \pi \cdot . q \wedge \varepsilon$ &.$/ .77997$ & $\wedge$ \\
\hline r/9V7人To & - / ITrrVI &.$/ T K \varepsilon O \varepsilon$ & $-\cdot / \cdot V \cdot T V \varepsilon$ & - rovvVI & • /r. Or & $\cdot / \Omega R V V V$ & 9 \\
\hline$\varepsilon /$ $M T 90 \varepsilon$ & ./TEYAIT & - /2O^OVA &.$/ 11 \wedge 7.1$ & $\cdot / 1 \cdot \varepsilon T \Lambda r$ &.$/ 199 \mathrm{VVV}$ & •/rl.rI & 1 . \\
\hline$r / 7020000$ &.$/ 27.919$ & $\cdot /$ VTOM & $-\cdot / T \cdot 09 \mathrm{~V}$. & ./IOOYM & $-\cdot / \cdot v \cdot v 0 \Lambda$ & -. rTV79T & 11 \\
\hline 0/ז007 & •/Vา7Y & $\cdot /$ rloz^1 & 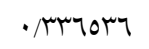 & $\cdot / 271 \cdot 17$ & $\cdot / \varepsilon 7 r \cdot \cdot 7$ & - rrolvV & ir \\
\hline$\varepsilon / \cdot r \varepsilon \mid V \cdot$ & - /09ruVr & . TONITE & - TVTTYE & $\cdot /$ K $\{70\{7$ &.$/ 1020 V 7$ & $\cdot / \sum \varepsilon V \cdot r \cdot$ & $1 \varepsilon$ \\
\hline 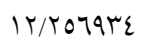 & $.109 V \pi 17$ & 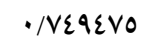 & .1000941 & . raritr & $\cdot /$ T09911 & 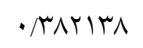 & 17 \\
\hline$\varepsilon / r \cdot V V r q$ & . TY0170 & -/70orvo & $\cdot / \varepsilon \wedge \varepsilon r q \mid$ & $\cdot / T|K| \wedge T$ & $\cdot / \Lambda \Upsilon \wedge \vee \varepsilon$ &.$/ 10.911$ & 11 \\
\hline r/AEVา & • $/$ TEY & • / RrYMAO & •/ITIEAT & $\cdot /$ TAVq. T & $\cdot / T V V \wedge q V$ & $\cdot / \cdot v \cdot 17$ & $r$. \\
\hline $\mid T / \varepsilon \varepsilon \varepsilon 7 \cdot 7$ & . NOEITE & -/VqEYOQ & - $/ 0 \varepsilon \varepsilon 194$ & . rovา7I & 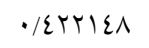 & $\cdot / 21 \pi / 7$. & $r \varepsilon$ \\
\hline$r / 277901$ & -.1 .91914 &.$/ 01194 \wedge$ & 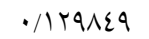 & . . &.$- / .09 \wedge \mu$ & . /EYTYTO & ro \\
\hline
\end{tabular}


طر احى الخُى بازار نقل و انتقالات بين الملى فو تباليستهاى...

\begin{tabular}{|c|c|c|c|c|c|c|c|}
\hline r/Ar990T & $.1 .9 r v r q$ & - /7roraq & $\cdot / T \cdot \varepsilon \varepsilon 7 \varepsilon$ & - rrotor & $\cdot / T Y V V \cdot 0$ & . & YT \\
\hline 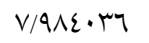 & . /199VAr & •/VEVAYA & . /T\&八৭YT & • • • vrrदq & $\cdot / T r \cdot \varepsilon \cdot r$ & $\cdot \pi \wedge 7 \cdot 91$ & TV \\
\hline $0 / 0 r \cdot 17 \pi$ & $\cdot 1 \cdot 9 \mathrm{~V} \cdot \mathrm{VA}$ & . ITYTVR & . /1rartz &.$/ 791911$ & • $/ \Psi \Sigma \Lambda \mu r$. & $\cdot 1 \cdot 7 \pi \cdot 70$ & rA \\
\hline Q/VITาEY & . TrAVIT & . IrTTVa & $\cdot / 11 r \cdot r \cdot$ & - honvir & • rIrror & $\cdot / 1 r \cdot 170$ & rq \\
\hline $1 \varepsilon / \cdot 7 \varepsilon \cdot 90$ & $. / 2 Y 10 . r$ &.$/ T V \varepsilon .07$ & . IYTMYOI & $\cdot / 177 \mid \cdot 0$ & •/471987 & $\cdot / 1 \cdot \Lambda 1 \varepsilon \wedge$ & r. \\
\hline $1 T / \varepsilon Y \varepsilon \wedge V 7$ & $\cdot \pi v \cdot|7|$ &.$/ 101149$ & $\cdot / l \varepsilon \varepsilon \varepsilon \mid V$ & $\cdot / 19 \cdot 94$. &.$/ \mu T \ldots .00$ & . •TYTIN & M \\
\hline rr/0709EV & - RV৭9\&l & - /209T00 & $\cdot / 47 V 109$ &.$/ 9.100 .9$ & $\cdot / 2 \wedge 79 \cdot 7$ & $\cdot / T \wedge V \cdot T \Lambda$ & Tr \\
\hline rI/9.10r & $\cdot / \varepsilon r 7 \mid \cdot r$ & 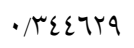 & . & •/194rroq & & - TOEVAV & TM \\
\hline $1 V / 797.92$ & $\cdot / \varepsilon q T V \cdot q$ & 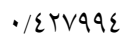 & $\cdot / T / 77 \varepsilon$. & $\cdot / \wedge \varepsilon \cdot \vee O \Lambda$ & • rvarzo & . rาव\&Vr & $r \varepsilon$ \\
\hline lN/ortrvt & سMNNOVR & $\cdot / r q \wedge I V$. & ./17rONE & $\cdot 11 \cdot 0 \cdot 70$ & • roOrNI & 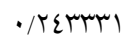 & ro \\
\hline$\varepsilon / \cdot 1 \wedge$ ror & • MTYYIV & . $/ 499049$ & . /T9Y人90 & .1010 .09 & •/YTA .. & $\cdot / \cdot 11 V \cdot 7$ & rᄉ \\
\hline$q / r q r \cdot T \Lambda$ & $\cdot / \varepsilon \varepsilon r \mu \cdot V$ & • /IMrV7o & . rrzoro9 & . IVIror & . Mro./. & . M19407 & $\varepsilon \varepsilon$ \\
\hline 19/901711 & . rlve. & Eרזrسז/. & • rVVVYr & $\cdot / \varepsilon r \cdot r q r$ & -/AOErAO & 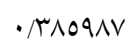 & 20 \\
\hline E/TrOTOE &.$/ 10 Y 100$ & $\cdot / \varepsilon V \cdot V \varepsilon q$ & $\cdot / T 1 \cdot 011$ & $\cdot / 1$ r $20 V 1$ & - /097HAE & - MrVAOQ & \{\rceil \\
\hline $1 \% / \cdot 1$ rTrE & $\cdot /|r T| \cdot 1$ & . & $.107 V 7 \ldots$ & $\cdot / r V \cdot O N r$ & 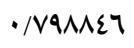 & $\cdot / \varepsilon \varepsilon 7 \varepsilon \wedge \Lambda$ & $\varepsilon V$ \\
\hline IN/AKZIKד & תr.9r. & $\cdot / T O \varepsilon \varepsilon \wedge 1$ & $\cdot / r q \mu \cdot v \varepsilon$ & 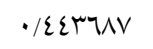 & - /VAOIOY & . & $\varepsilon \wedge$ \\
\hline$\varepsilon / V \wedge 9 \varepsilon r \varepsilon$ & $\cdot / \varepsilon V \cdot q v \varepsilon$ & $\cdot / r \varepsilon q \cdot q$. & ./ITVIr. & . /2T007r & . & $\cdot / I V R v \cdot T$ & 01 \\
\hline $0 / 1 \mu \wedge \cdot 10$ & . / & •/r人974ו & $\cdot / l \varepsilon \cdot v 7 \Lambda$ & $\cdot / r \wedge \wedge \varepsilon \cdot r$ & $\cdot / 7.7997$ & $\cdot \pi \mid \wedge \varepsilon V R$ & or \\
\hline $9 / 9 \varepsilon \cdot r 09$ & $\cdot / 1 \wedge \varepsilon 7 \cdot q$ & 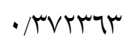 & . & . roqr々八 & -/2OrqTI &.$/ 72197$. & or \\
\hline Ir/AVruvo & מזוגואי• & $\cdot / 297092$ & •/vArITA & . /rTq91. & - rvorno & $\cdot / O r V \cdot r A$ & or \\
\hline$r \cdot / 0 v \cdot q \varepsilon$. & $\cdot / \mu 1 \cdot \wedge 9$. &.$/ 01170 \mathrm{~V}$ & •/ATATrV & . TO1NTE & $\cdot|\varepsilon r| \cdot 91$ & $\cdot / v \cdot 99 r V$ & 00 \\
\hline IV/orn. I. & $\cdot / 1 \vee \varepsilon \wedge \cdot \varepsilon$ & . ह TO10T & •/ArrVOA & 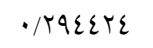 & •/TIONKA & . /29rา119 & 07 \\
\hline$|r /| \mid \varepsilon \cdot r \varepsilon$ & $\cdot / r \cdot V|r|$ & $\cdot / 219701$ & $\cdot|\wedge r \cdot \varepsilon q|$ & מוז97ות & • rVVqAr &.$/ 07 \varepsilon \wedge 0$. & OV \\
\hline V/A.rیVT & $\cdot 1 \cdot v \cdot \cdot 1 r$ & . TTONTA & . ITYTYEO & $-\cdot / \cdot \cdot v \cdot \cdot 1$ & $\cdot /$ TVqIYq & . & $O \wedge$ \\
\hline V/AVYqT7 & - / $\wedge \wedge O Y$. & 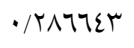 & 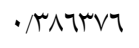 & $-.1 \cdot 1 \cdot 1897$ & $\cdot / 471 \cdot 17$ & ערזrrר/. & 09 \\
\hline $10 / 2979 \mathrm{VV}$ & $\cdot 1 \cdot 1 V \cdot 7 r$ & $.101870 \mathrm{~V}$ & - NYYZT. $r$ &.$/ 11071 \mathrm{r}$ & 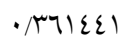 & - /Arrt7o & 7. \\
\hline V/ONrunv & - Mrorla & سKTIKI & $\cdot / r T \cdot \wedge r$. & $\cdot / r 01011$ & . r ₹rolq & $\cdot / 779 r \cdot \varepsilon$ & 71 \\
\hline N/QTr.TV & $\cdot / \cdot r \cdot V Y T$ & $\cdot / 710110$ &.$/ 0010 \mathrm{~V}$ & 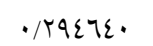 & 1 & -NYYEYI & Tr \\
\hline
\end{tabular}

جدول 7 گويهها، بارهاى عاملى و مقدار t يرسشنامة نهايى را نشان مىدهد. 
جدول 9. كو يه ها، بارهاى عاملى و ميزان معنى دارى برسشنامهُ نهايى (سT كو يهاى)

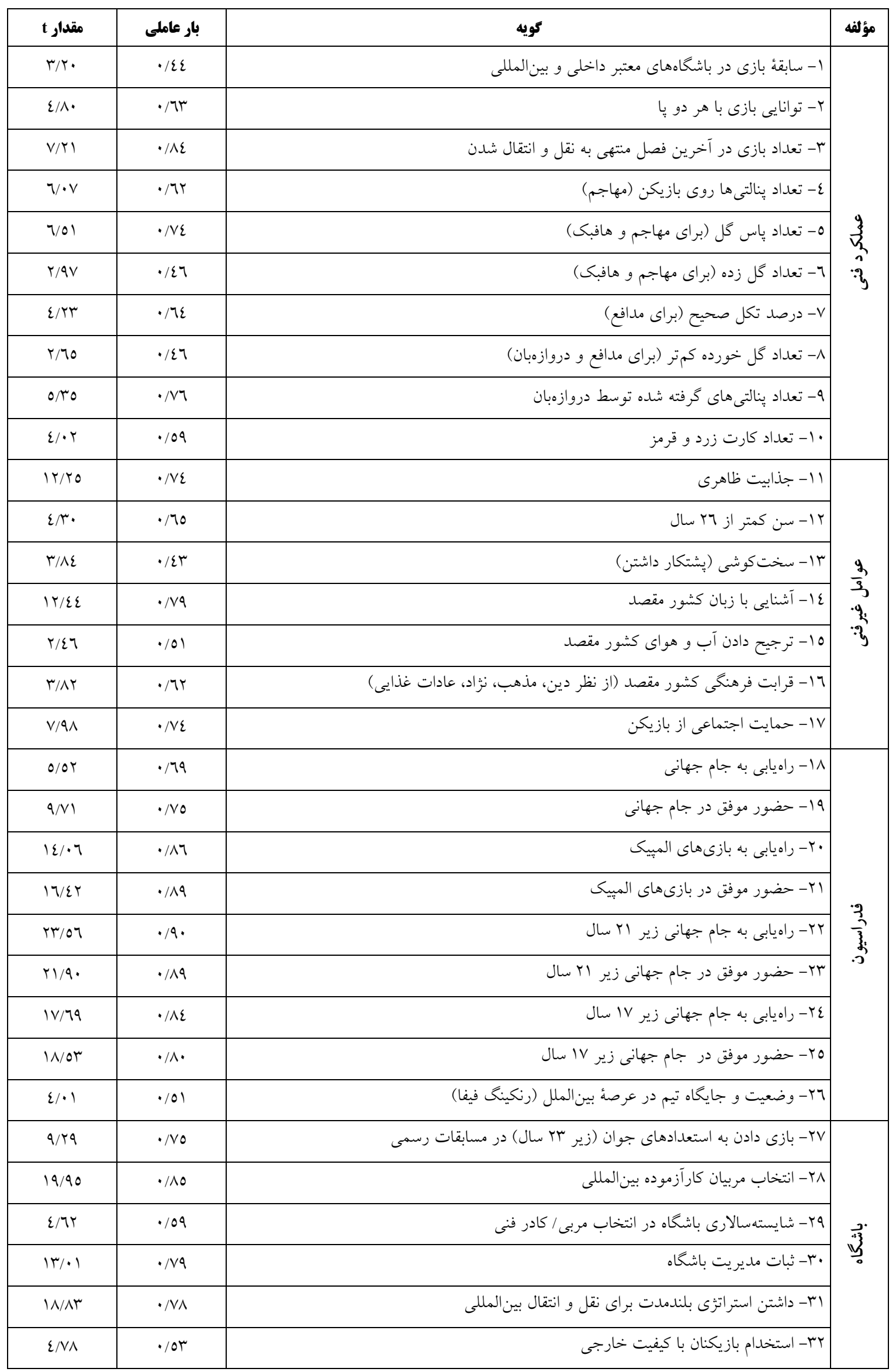




\begin{tabular}{|c|c|c|}
\hline $0 / 11$ & $\cdot / 7$ & سM- مشاركت آكادمى باشخاه با باشگحاههاى استعدادياب ارويايى \\
\hline $9 / 9 \varepsilon$ & $\cdot / \mathrm{M}$ & عץ- تسهيل قوانين نظام وظيفه عمومى براى نقل و انتقال فوتباليست \\
\hline$\| r / A V$ & $\cdot / \mathrm{VA}$ & هץ- خصوصى سازى باشخاههاى فوتبال \\
\hline$r \cdot / 0 V$ & $\cdot / \wedge 7$ & 7r- حمايت مالى از باشخاه \\
\hline IV/Or & •/AK & 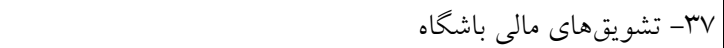 \\
\hline$|r /| \mid$ & •/Ar & ^ז"- خطمشى هاى مالياتى براى باشخاه \\
\hline$V / \Lambda \cdot 7$ & $\cdot / \mathrm{N}$ & qج- مشاوره به بازيكن در انتخاب باشخاه \\
\hline $\mathrm{V} / \mathrm{AV}$ & $\cdot / 7 r$ & •ع- كمك به بازيكن در تعيين حقوق (دستمزد) \\
\hline $10 / 29$ & $\cdot / \wedge r$ & ا ع- مهارت در \\
\hline $\mathrm{V} / 0 \wedge$ & $\cdot / 77$ & ب إرتباطات كسترده \\
\hline N/9T & $\cdot / \mathrm{VY}$ & سع- بروز بودن اطلاعات مدير برنامه در نقل و انتقال بازيكن \\
\hline
\end{tabular}

ملاكى ديخر بررسى بايايى سازههاى تحقيق، يايايى تركيبى سازهها مىباشد كه سطح قابل قبول براى آن N/ • و بالاتر مىباشد. مقادير

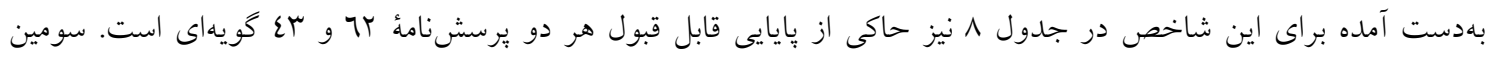

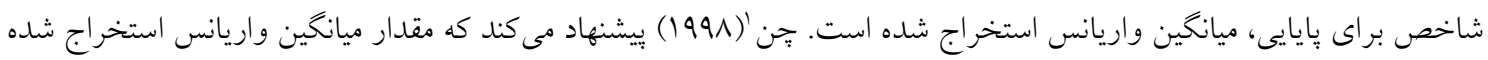

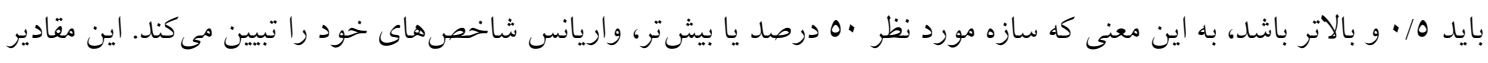

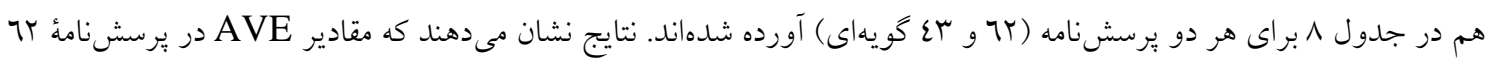

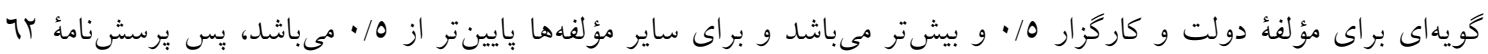

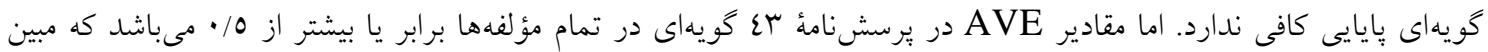

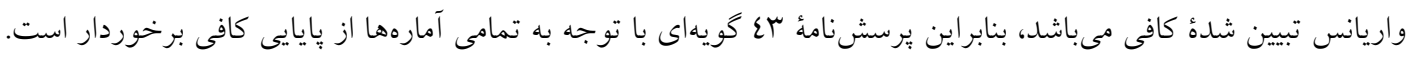

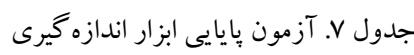

\begin{tabular}{|c|c|c|c|c|c|c|}
\hline \multicolumn{2}{|c|}{ AVE } & \multicolumn{2}{|c|}{ پايايى تركيبى } & \multicolumn{2}{|c|}{ آلفاى كرونباخ } & \\
\hline ير سشنامة ب F كويهاى & 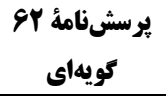 & 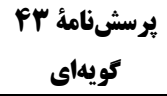 & كوسئاى & 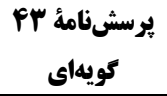 & كو توشيهاى & \\
\hline$\cdot 10$ & $\cdot / \pi q$ & $\cdot / \wedge 7$ & $\cdot / 10$ & $\cdot / A r$ & $\cdot / \wedge$ & عملكرد فنى \\
\hline$\cdot / 0 r$ & $\cdot / \tau \varepsilon$ & •/^ז & $\cdot / 10$ & $\cdot / \mathrm{VA}$ & - /Ar & عوامل غيرفنى \\
\hline$\cdot / 70$ & $\cdot / 70$ & $\cdot / 9$. &.$/ 9$. & $\cdot / \wedge 7$ & $\cdot / \wedge 7$ & دولت \\
\hline$\cdot / 7 \varepsilon$ & $\cdot / 27$ & $\cdot / 9 \varepsilon$ &.$/ 9 T$ & $\cdot / 9 r$ & $\cdot / 9$ & فدراسيون \\
\hline$\cdot 10$ & $\cdot / / q$ & $\cdot / \wedge V$ & $\cdot / \wedge \mathrm{V}$ & •/Ar & • & باشخاه \\
\hline .100 & .10 & • - (A & • & $\cdot / V 7$ & $\cdot / \mathrm{VI}$ & كار گزار \\
\hline
\end{tabular}

براى روايى (اعتبار افتراقى) سازهها، فرنل و لاكر (1911) بيشنهاد مى كند كه جذر ميانكين واريانس استخراج شده هر متغير بايد

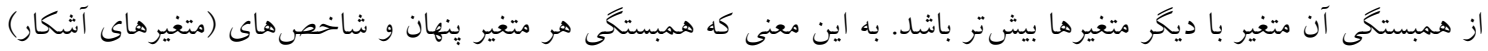

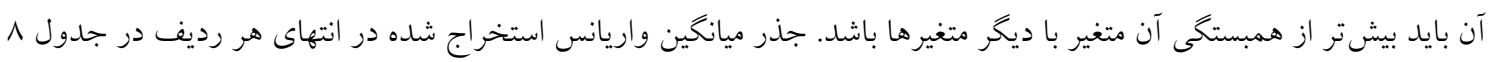


آورده شده است. مشاهده مىشود مقادير مربوط به هر متغير از همبستخى هر متغير با ديخر متغيرها بيشتر است و اين نشان دهنده روايى قابل قبول ابزار اندازهيرى است.

جدول 1 ماتريس همبستخى متغير هاى تحقيق و جذر AVE

\begin{tabular}{|c|c|c|c|c|c|c|}
\hline 9 & $\Delta$ & $f$ & $r$ & $r$ & 1 & متغيرها \\
\hline & & & & & $\cdot / v$ & ا - عملكرد فنى \\
\hline & & & & $\cdot / V r$ & $\cdot / \varepsilon \varepsilon 0^{*}$ & ץ- عوامل غيرفنى \\
\hline & & & $\cdot / \Lambda$. & $\cdot 107 \mathrm{~h}^{* * *}$ & $\cdot / T A V$ & r- دولت \\
\hline & & $\cdot / \wedge$. & . Tar & - rar & $\cdot / 20 Y^{*}$ & ع- فدراسيون \\
\hline & $\cdot / v$ & $\cdot / \varepsilon$ V* $^{*}$ & $\cdot / 209^{*}$ & $\cdot / \varepsilon \cdot \wedge^{*}$ & $\cdot / \varepsilon \varepsilon 7^{*}$ & 0- باشخاه \\
\hline$\cdot / \sqrt{ } \varepsilon$ & $\cdot / \varepsilon V r^{* *}$ & $\cdot / M Y I$ & $\cdot N \mu^{*}$ * * & $\cdot / \varepsilon \curlyvee \Lambda^{*}$ & - ror & ד- كار گزار \\
\hline
\end{tabular}

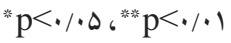

شكل ا مدل بررسى شده در اين تحقيق را نشان مىدهد. بررسى ارتباط متغيرها در PLS از طريق ضرايب مسير (ß) انجام

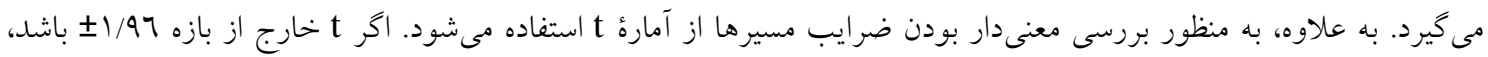

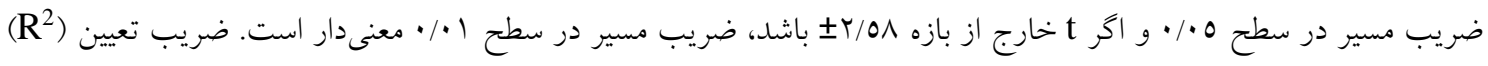

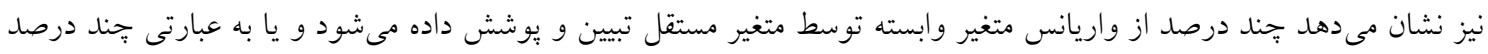
از تغييرات متغير وابسته ناشى از متغير يا متغيرهاى مستقل است.

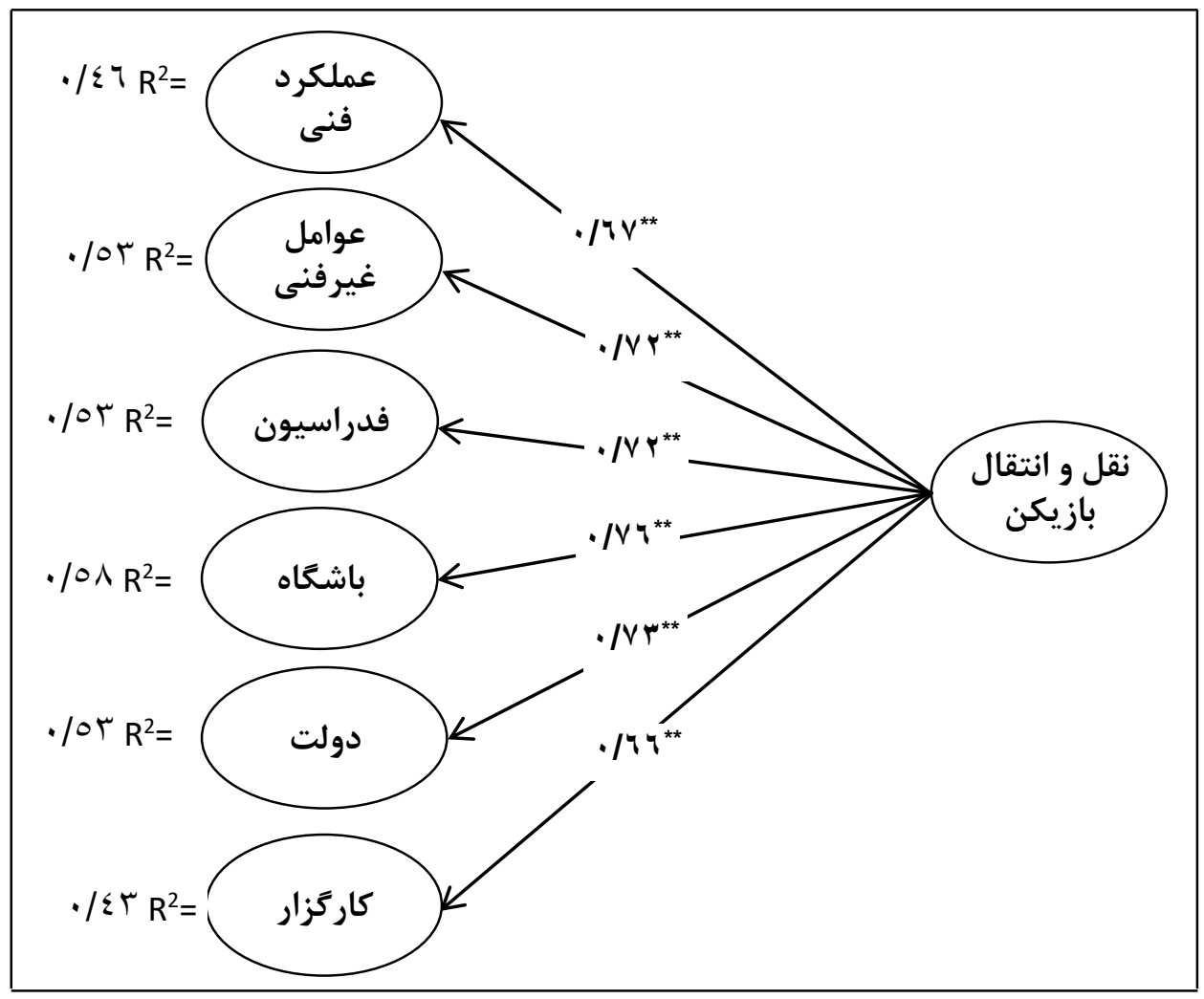

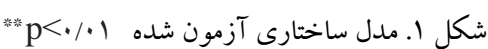




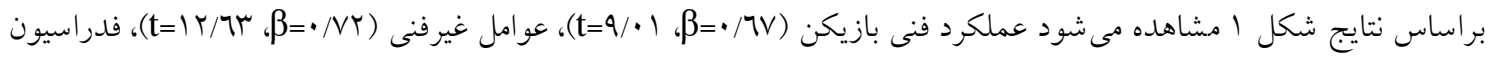

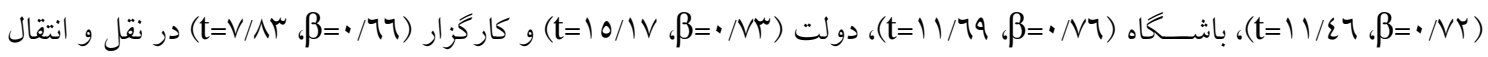

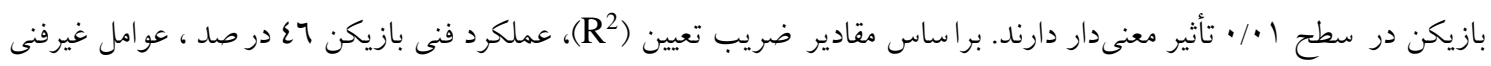

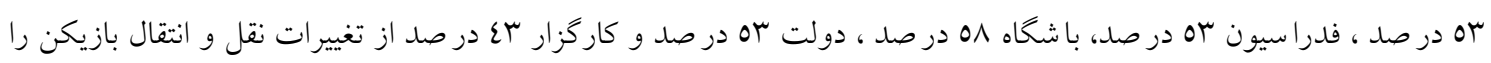

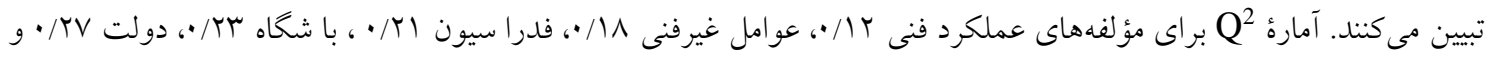

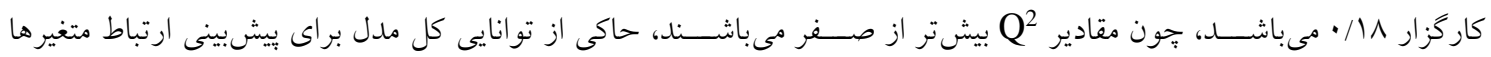

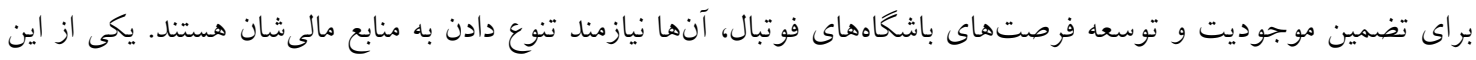

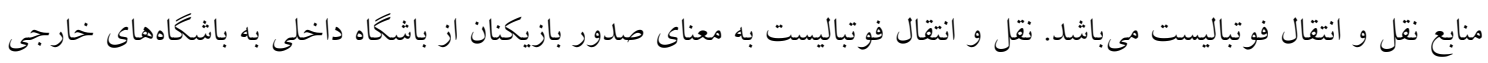

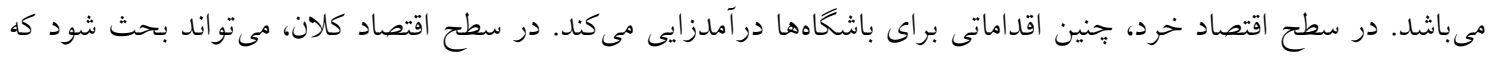

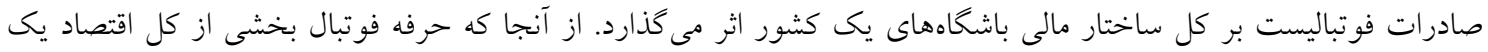

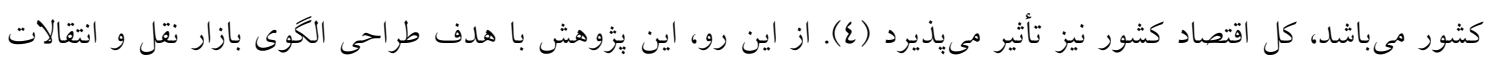

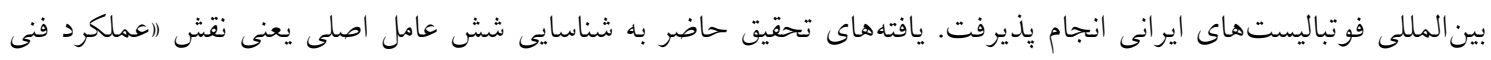

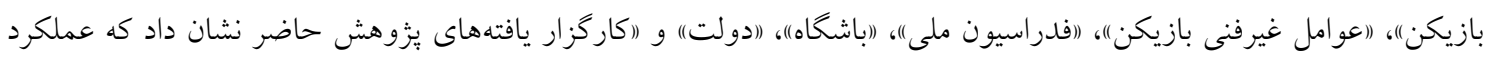

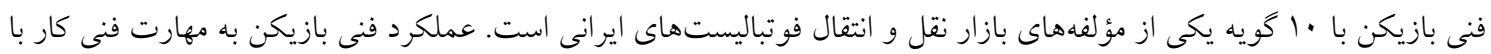
تو

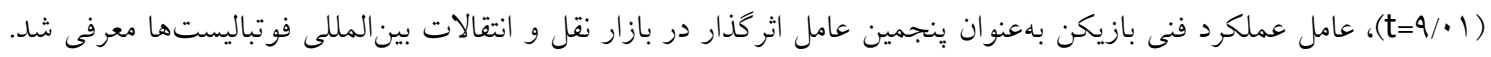

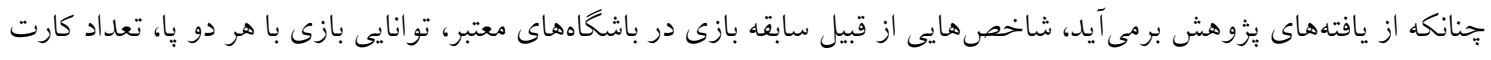

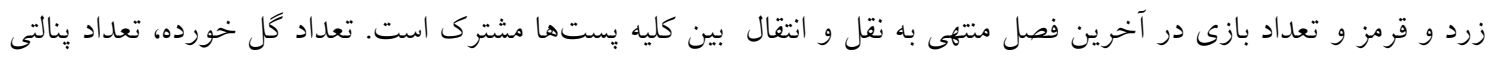

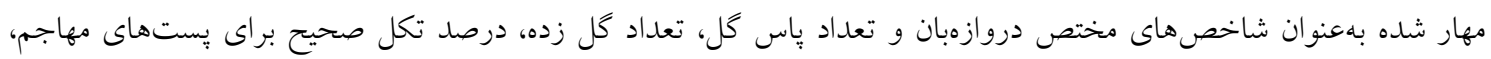

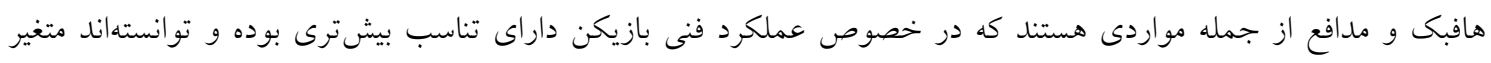

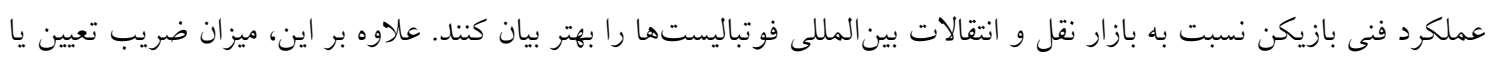

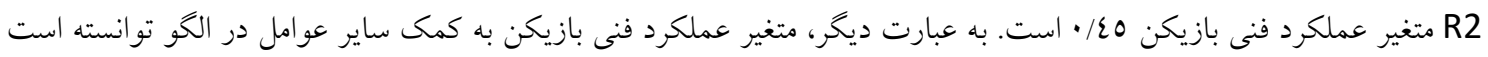

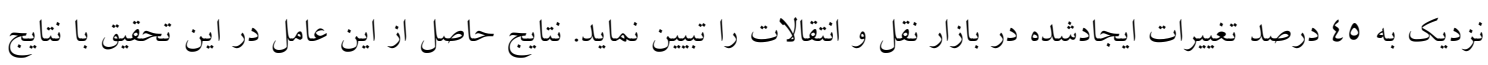

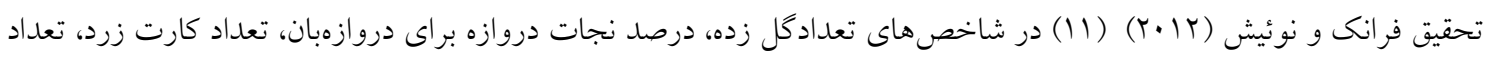

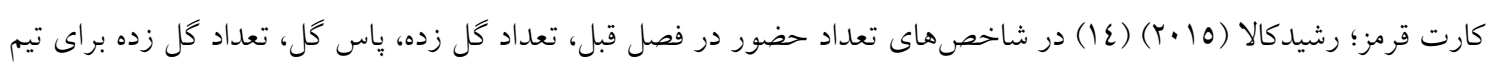

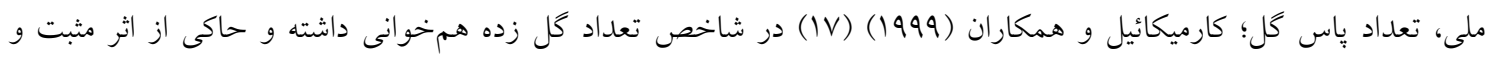

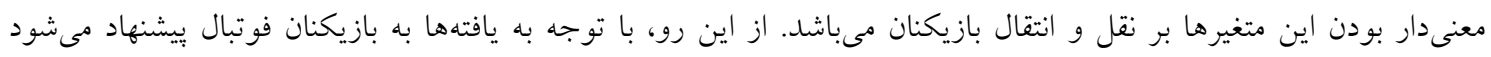

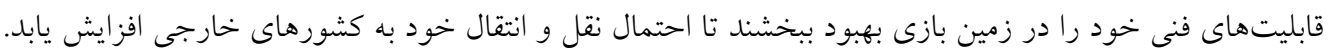

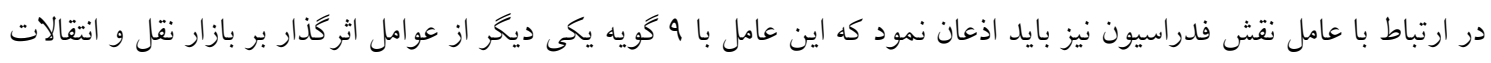

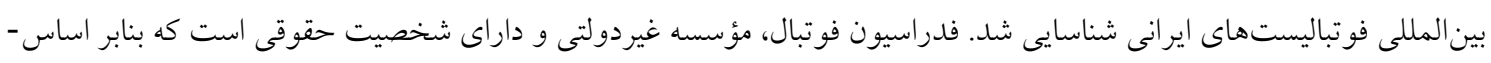

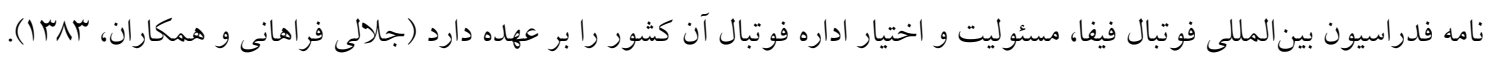
در تحليل كمى، با توجه به ضريب تأثير (

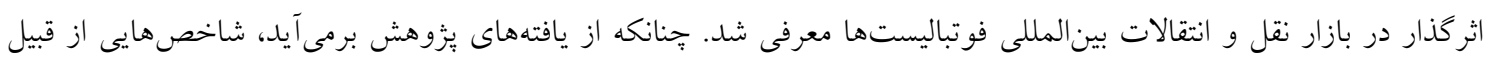

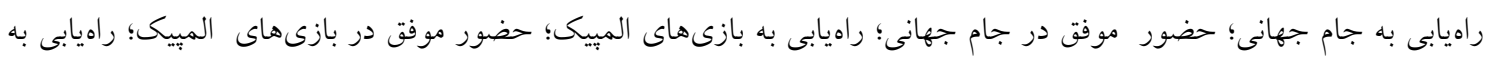

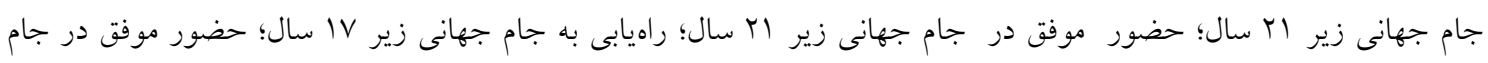


جهانى زير VI سال؛ و وضعيت و جايگاه تيم در عرصه بينالملل (رنكينخ فيفا) از جمله مواردى هستند كه در خصوص فدراسيون

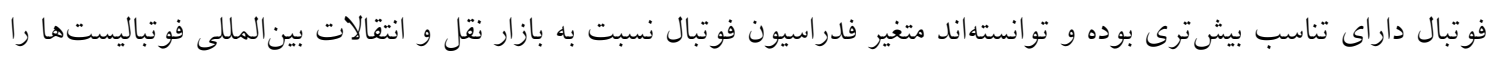
بهتر بيان كنند. علاوه بر اين، ميزان ضريب تعيين يا R2 متغير فدراسيون فوتبال Or/ • است. به عبارت ديخر متغير فدراسيون فوتبال

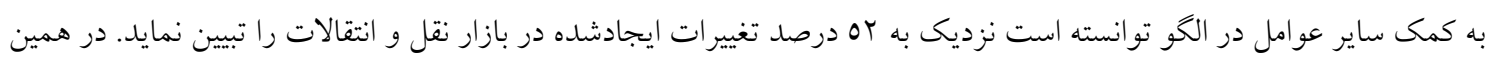

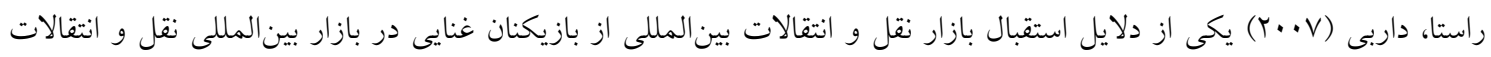

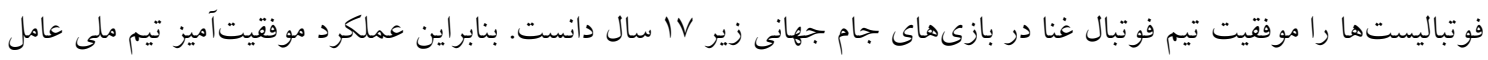

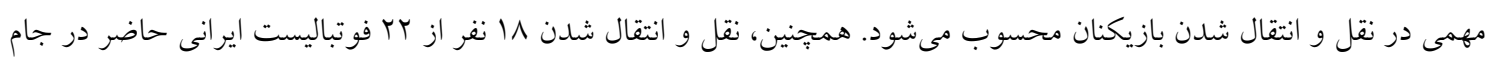

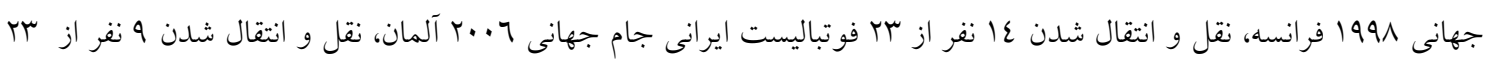

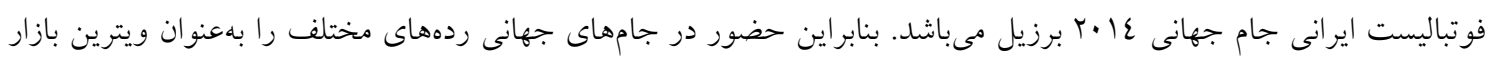

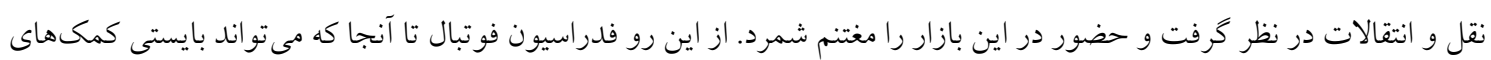
مادى و معنوى براى رسيدن تيمهاى ملى به جام جهانى در ردههاى مختلف فراهم آورد.

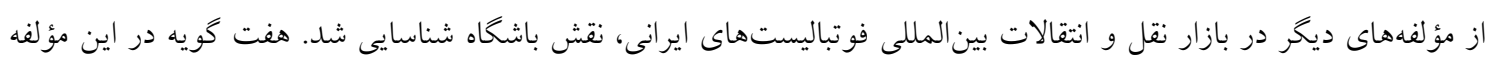

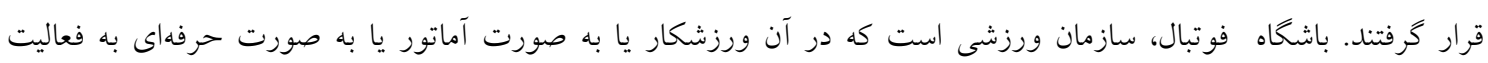
مى بردازد. در تحليل كمى، با توجه به ضريب تأثير (

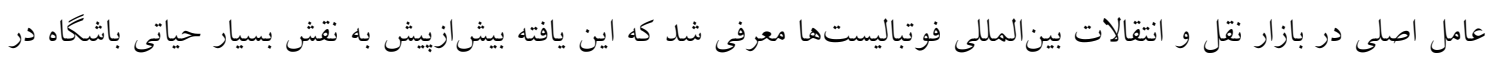

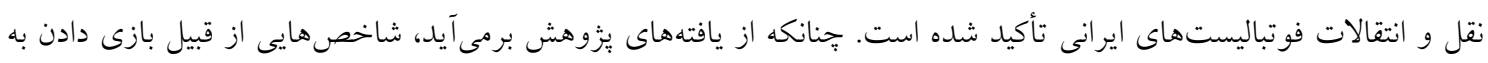

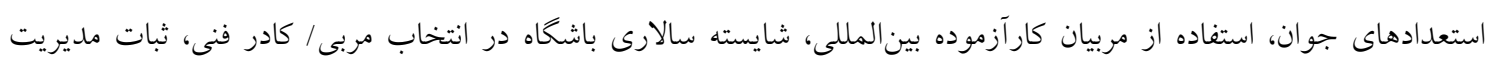
باشگاه، داشتن استراتزى براى نقل و انتقال بين المللى، استخدام بازيكنان با كيفيت خارجى، مشاركت آكادمى باشخاه با باشخاههاى

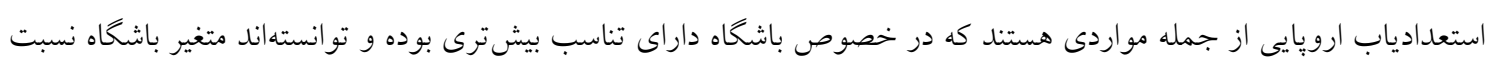

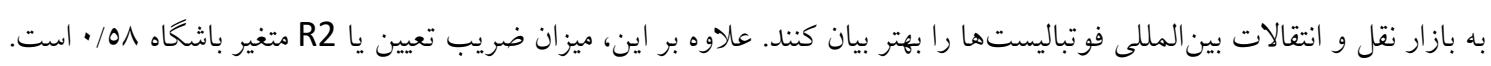

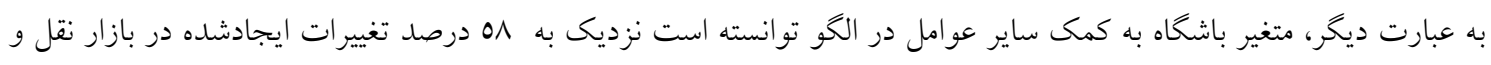

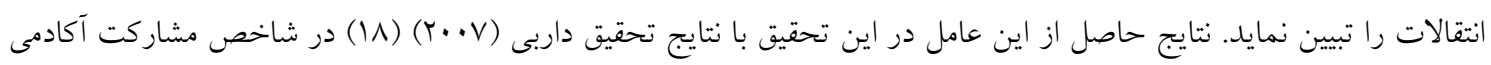

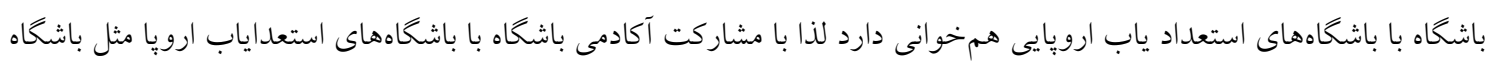

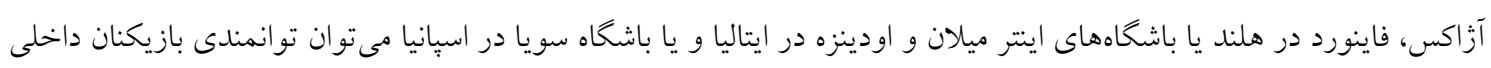

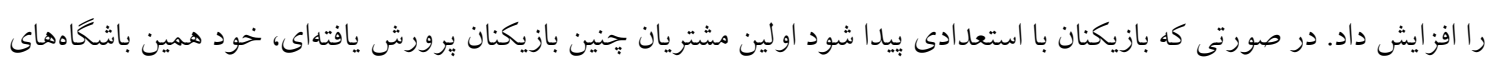

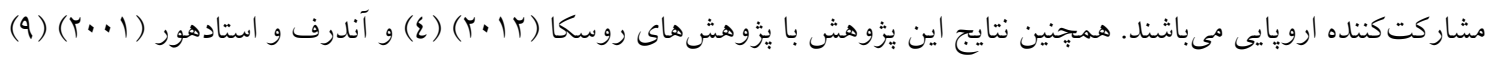

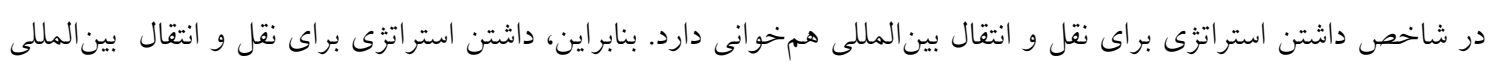

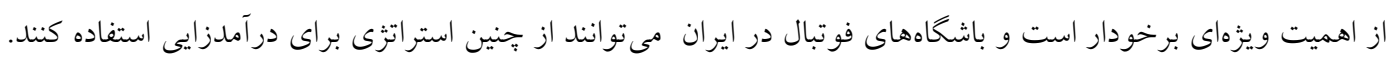

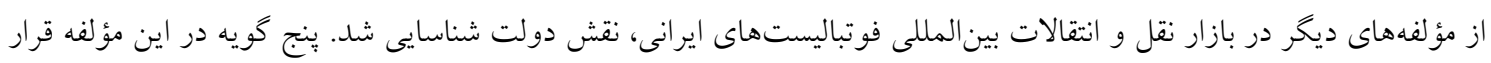

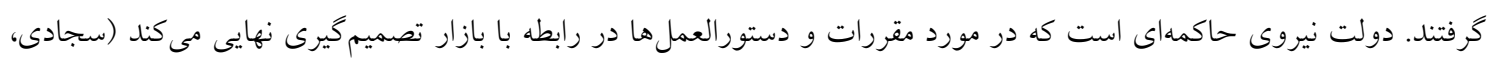

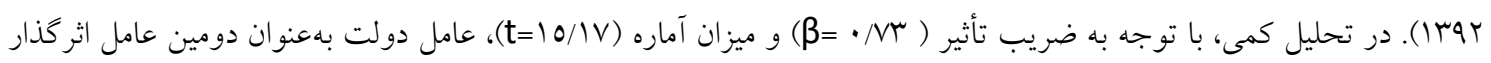

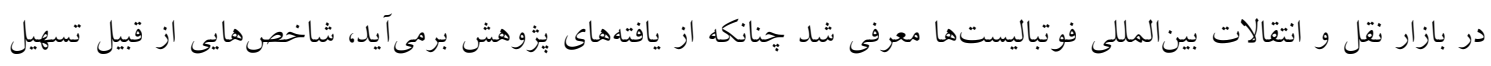

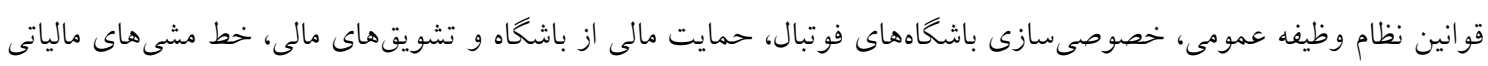
از جمله مواردى هستند كه در خصوص دولت داراى تناسب بيشترى بوده و توانستهاند متغير دولت نسبت به بازار نقل و انتقالات

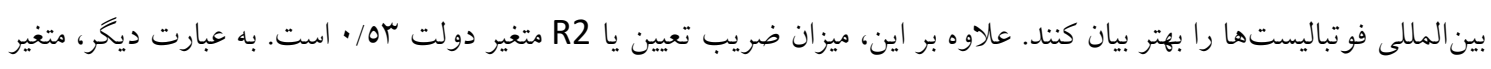
دولت به كمك ساير عوامل در الخو توانسته است نزديك به سه درصد تغييرات ايجادشده در بازار نقل و انتقالات را تبيين نمايد.

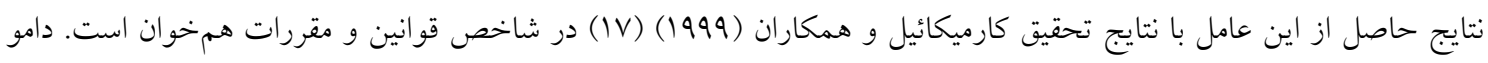

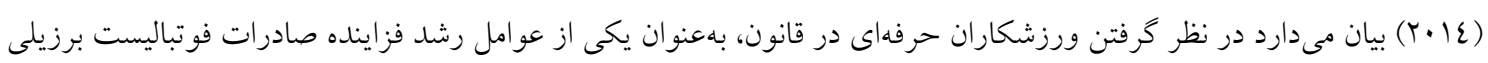


مىباشد (YI). بنابراين، در كشور ايران نيز مىتوان به حذف سربازى براى بازيكنان نقل و انتقال شده، بهعنوان راه كار حقوقى

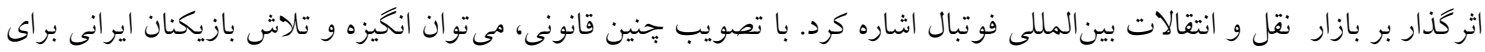
نقل و انتقال بين المللى را افزايش داد.

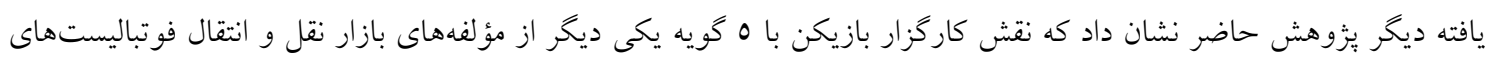

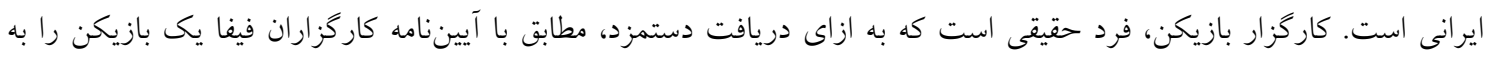

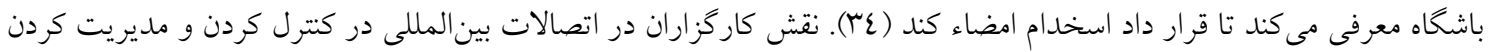

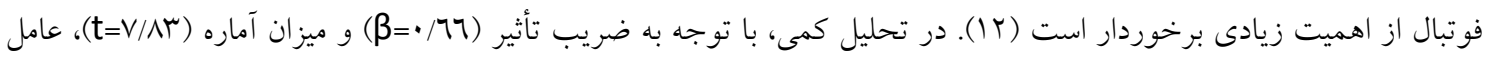

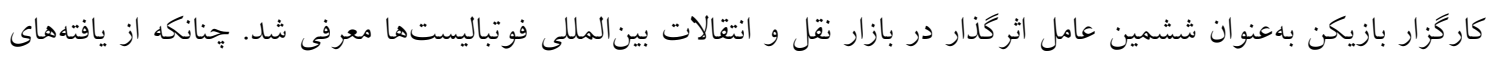

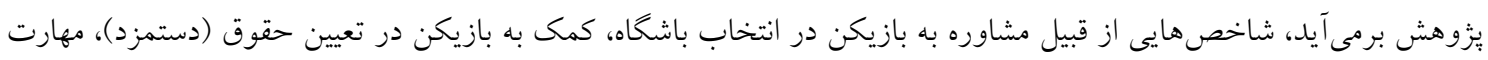

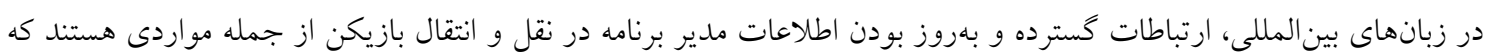
در خصوص كار گزار بازيكن داراى تناسب بيشترى بوده و توانستهاند متغير كارگزار بازيكن نسبت به بازار نقل و انتقالات بين المللى دانى

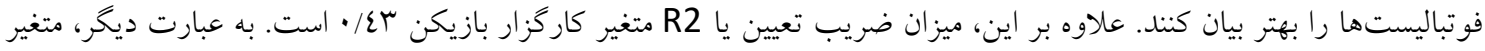

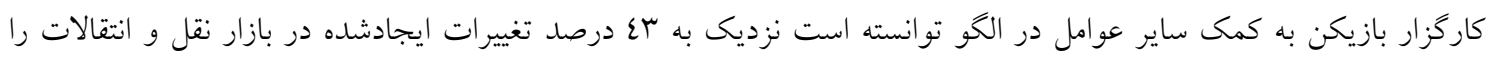

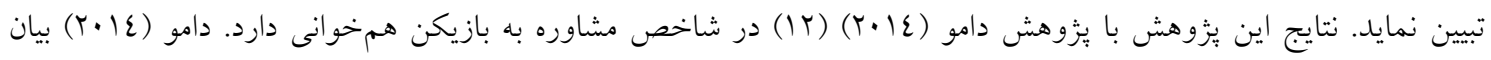

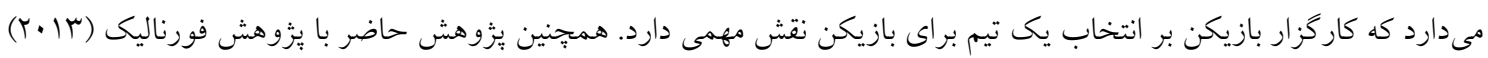
در شاخص كمك به بازيكن در تعيين حقوق (دستمزد) بازيكن، بهروز بودن اطلاعات همخوانى دارد. از آنجا كه كاركزار بازيكن مىتواند نقش موكل فرد را ايفا كند (r) و تجربه بيشترى در تنظيم طول قرارد استخدام بازيكن دارند (عاع). بنابراين، انتظار

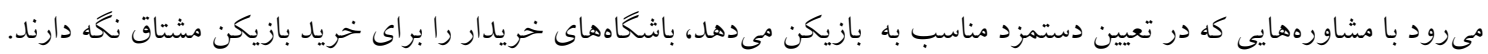

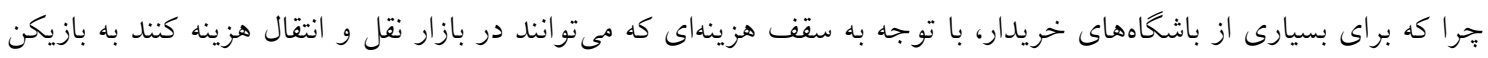

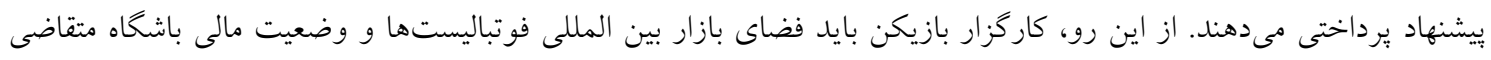

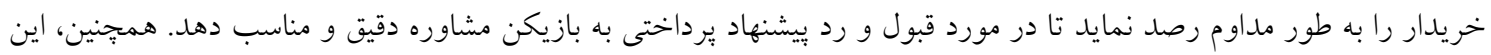

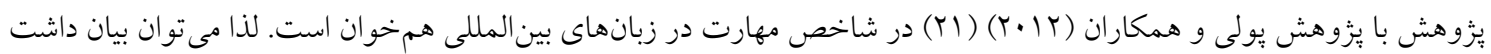

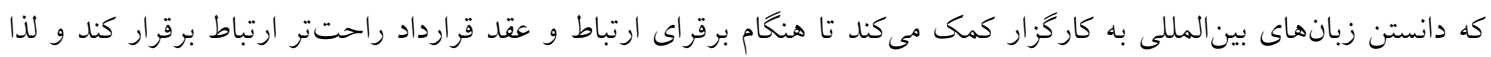

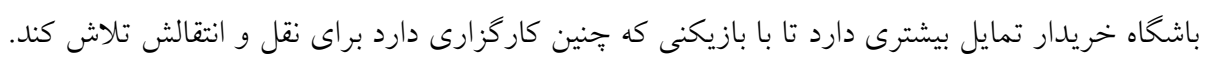

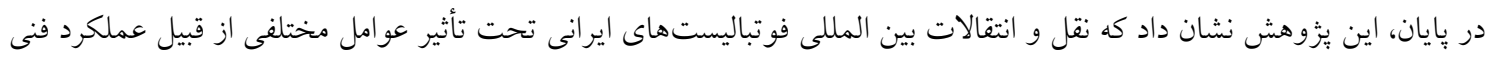
بازيكن، عملكرد غيرفنى بازيكن، باشخاه، فدراسيون، دولت، مدير برنامهاى بازيكن مى باشد. با توجه به اينكه بازار نقل و انتقالات

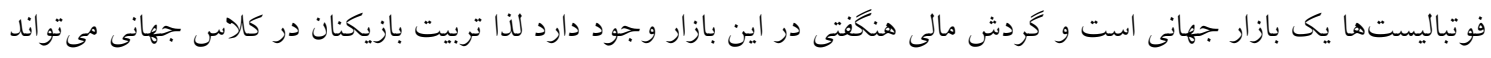

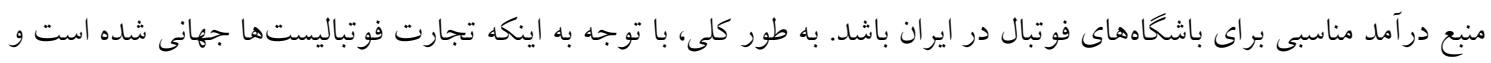

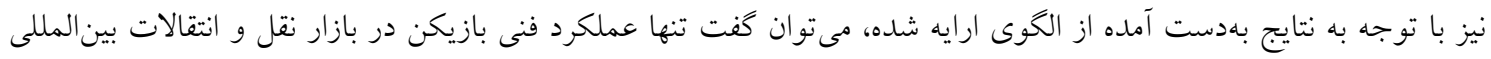

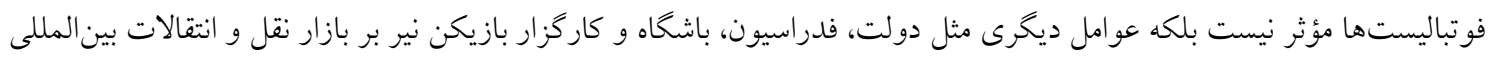

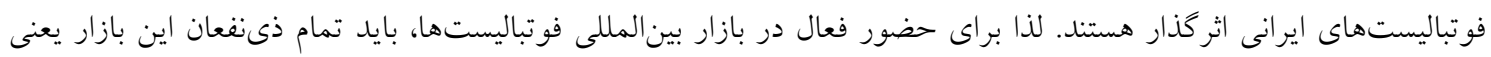

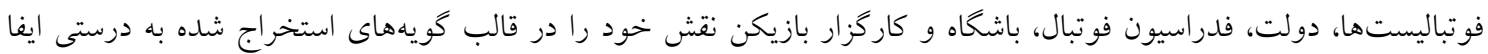

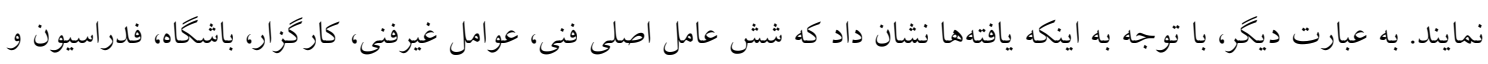

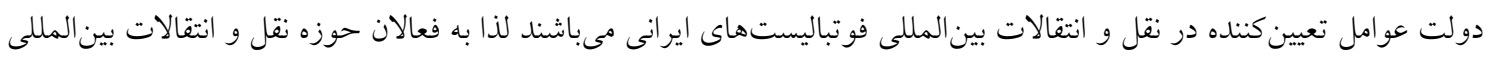

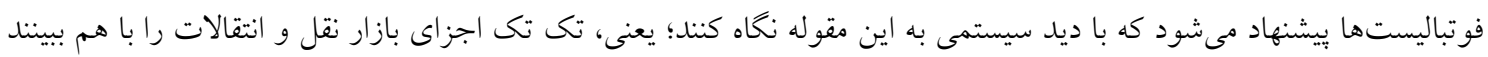

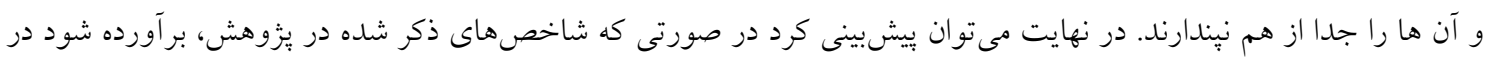

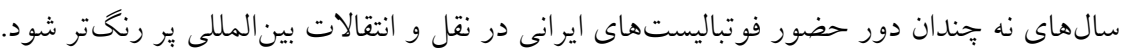


هر ثيزوهشى با محدوديت هايى مواجه است كه يزووهش حاضر نيز از اين قاعده مستثنى نيست. براى مثال در عموم تحقيقات خارجى دادههاى و اقعى كه بازيكنان بر اساس آنها عملكرد آنها سنجيده مىشود آزمون شدهاند اما در يزوهش حاضر به دليل نبود (آمارهاى عملكرد فردى بازيكنان) انجام مقايسه عادلانه وجود ندارد. بنابراين بيشنهاد مىشود انجام تحقيقى با دادههاى واقعى عملكرد فنى بازيكنان صورت كيرد. عالوه بر اين همان گونه كه اشاره شده بازار نقل و انتقالات به دو بخش داخلى و بين المللى تقسيم مىشود و در بعضى مواقع تداخل عوامل بيش ميى آيد بنابراين بيشنهاد مىشود در بيزوهشى جداگانه به طراحى الكوى بازار نقل و انتقالات داخلى يرداخته شود. همجنين بيشنهاد ميىشود در بيزوهش جداكانه و با استفاده از مطالعه نظريه داده بنياد الكوى

$$
\text { يارادايمى انجام شود و مقايسهاى بين الخوى كمى و كيفى صورت كيرد. }
$$

\section{من}

1. Symanski, Stefan. (2009). Playbooks and checchbooks: an introduction to economics of modern sports. Princeton University Press.

r. Oprean, Victor-Bogdan \& Oprisor, Tudor. (2014). Accounting for soccer players: capitalization paradigm vs. expenditure. Procedia Economics and Finance, 15, 1647 - 1654.

r. Jarvandi, Ali. (2014). Modeling Team-Compatibility Factors Using a Semi-Markov Decision Process: A Framework for Performance Analysis in Soccer. Dissertation thesis, The Faculty of The School of Engineering and Applied Science, The George Washington University.

$\varepsilon$. Rosca, Vlad. (2012). The Financial Contribution of International Footballer Trading to the Romanian Football League and to the National Economy. Theoretical and Applied Economics Volume XIX, No. $\varepsilon(079)$, pp. $1 \leqslant 0-177$.

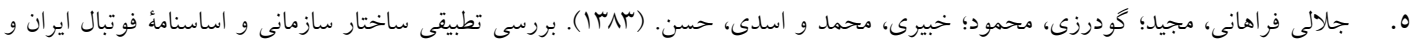

$$
\begin{aligned}
& \text { كشورهاى منتخب و ارائه الكوى بهينه.نشريه حركت، شماره }
\end{aligned}
$$

7. Miao He. (2015). Exploring the Relationship between Football Players Performance and Their Market Value. Unpublished Master Thesis, Leiden University, Netherlands.

v. Poli, Raffaele., Ravenel, Loïc \& Besson, Roger. (2015). Transfer expenditure and results. CIES Football Observatory Monthly Report Issue no. 3 - March.

^. Fløtnes, T.G. (2011). Factors of success for Norwegian top football clubs. M. Sc. Thesis, Copenhagen Business School, Denmark.

१. Andreff, Wladimir \& Staudohar, Paul. D. (2000). The Evolving European Model of Professional Sports Finance. Journal of sport economics, Vol. 1 No. 3, 257-276.

1. Ruijg, J \& van Ophem, H. (2015). Determinants of football transfers, Applied Economics Letters, 22 (1), 12-19.

11. Franck, F \& Nuesch, S. (2012). Talent and/or popularity: what does it take to be a superstar? Economic Inquiry, Vol. 50, No. 1, 202-216.

ir. Damo, A. S. (2014). Training soccer players in Brazil. Soccer \& Society, 15(1), 93-107.

1r. Herberger, Tim A. \& Wedlich, Florian. (2016). What Athletic Characteristics Determine Professional Football Players' Market Values: A Crowd sourced Valuation, Discussion Paper No. 16-23, German Economic Association of Business Administration.

I . Rachid Kalla, Abdoul. (2015). Analysis of variables which determine football player market value. Master thesis.

10. Bryson, A., Frick, B., \& Simmons, R. (2009). The Returns to Scarce Talent: Footedness and Player Remuneration in European Soccer. Journal of Sports Economics, 000(00) 1-23.

17. Lehmann, E., \& Schulze, G. (2005). What does it take to be a star? The role of performance and the media for German Soccer Players. Mimeo, Department of Economics and Management, University of Augsburg.

Iv. Carmichael, F., Forrest ., D., \& Simmons, R. (1999). The labour market in association football: who gets transferred and for how much? Bulletin of Economic Research, 51(2), 125-150.

1^. Darby, Paul., Akindes, Gerard, \& Kirwin, Matthew. (2007). Football Academies and

the Migration of African Football Labor to Europe. Journal of Sport \& Social Issues, Volume 31 Number 2, 143-161.

19. Athanasios, Douros. (2013): Finance and football. The market reaction to football player transfers in Europe. Master thesis, university of Van Tilburge, School of Economics and Management, Netherland.

$r \cdot$. Rohde, Marc, \& Breuer, Christoph. (2016). Europe's Elite Football: Financial Growth, Sporting Success, Transfer Investment, and Private Majority Investors. International Journal of Financial Studies, 4, 2, 120.

r. Poli, Raffaele., Rossi, Giambattista, \& Besson, Besson. (2012). Football agents in the biggest five European football market: an empirical research report, CIES football observatory.

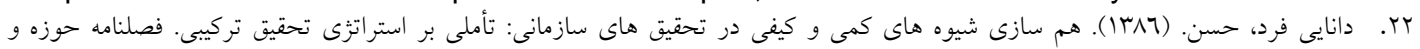

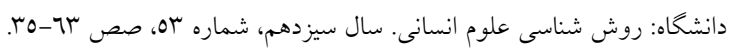


rr. Creswell, J. W. (2013). Research design: qualitative, quantitative, and mixed methods approaches. Washington DC: SAGE Presss Inc.

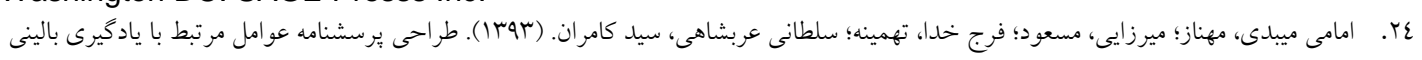

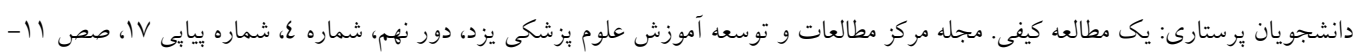

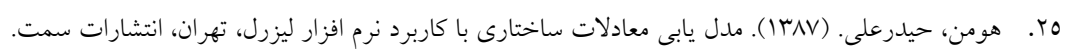

r. Chin, W. W. (1998). The partial least squares approach to structural equation modeling. Modern methods for business research, 29(2), 295-336.

rv. Fornell, C., \& Larcker, D. F. (1981). Evaluating structural equation models with unobservable variables and measurement error. Journal of marketing research, 18(1), 39-0.

ץ^. András, Zsolt \& Havran, Krisztina. (2014). Regional Export Efficiency in the Market of Football Players. 'Club of Economics in Miskolc' TMP 10 (2), 3-15.

rq. Dobson, Stephan \& Goddard, John. (2011). The economics of football. Second edition, Cambridge university press.

r. Herberger, Tim A. \& Wedlich, Florian. (2016). What Athletic Characteristics Determine Professional Football Players' Market Values: A Crowd sourced Valuation, Discussion Paper No. 16-23, German Economic Association of Business Administration.

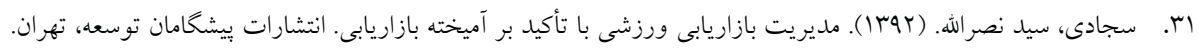

$$
\begin{aligned}
& \text { rrr. }
\end{aligned}
$$

rr. Monk, D., \& Russell, D. (2000). Training apprentices: Tradition versus modernity in the football industry, Soccer \& Society, 1(2), 62-79.

Fornalik, Jakub. Andrzej. (2013). Players' Agents' Role in Football Transfer Market: Evaluating the. Need of Improving FIFA Regulations. Chicago-Kent College of Law, Entertain 